\title{
THESIS
}

\section{A METHOD TO DOWNSCALE SOIL MOISTURE TO FINE-RESOLUTIONS USING TOPOGRAPHIC, VEGETATION, AND SOIL DATA}

\author{
Submitted by \\ Kayla J. Ranney \\ Department of Civil and Environmental Engineering
}

In partial fulfillment of the requirements

For the Degree of Master of Science

Colorado State University

Fort Collins, Colorado

Fall 2014

Master's Committee:

Advisor: Jeffrey D. Niemann

Timothy R. Green

Stephanie K. Kampf 
Copyright by Kayla J. Ranney 2014

All Rights Reserved 


\section{A METHOD TO DOWNSCALE SOIL MOISTURE TO FINE-RESOLUTIONS USING} TOPOGRAPHIC, VEGETATION, AND SOIL DATA

Various remote-sensing and ground-based sensor methods are available to estimate soil moisture over large regions with spatial resolutions greater than $500 \mathrm{~m}$. However, applications such as water management and agricultural production require finer resolutions $(10-100 \mathrm{~m}$ grid cells). To reach such resolutions, soil moisture must be downscaled using supplemental data. Several downscaling methods use only topographic data, but vegetation and soil characteristics also affect fine-scale soil moisture variations. In this thesis, a downscaling model that uses topographic, vegetation, and soil data is presented, which is called the Equilibrium Moisture from Topography, Vegetation, and Soil (EMT+VS) model. The EMT+VS model assumes a steady-state water balance involving: infiltration, deep drainage, lateral flow, and evapotranspiration. The magnitude of each process at each location is inferred from topographic, vegetation, and soil characteristics. To evaluate the model, it is applied to three catchments with extensive soil moisture and topographic data and compared to an Empirical Orthogonal Function (EOF) downscaling method. The primary test catchment is Cache la Poudre, which has variable vegetation cover. Extensive vegetation and soil data were available for this catchment. Additional testing is performed using the Tarrawarra and Nerrigundah catchments where vegetation is relatively homogeneous and limited soil data are available for interpolation. For Cache la Poudre, the estimated soil moisture patterns improve substantially when the vegetation and soil data are used in addition to topographic data, and the performance is similar for the 
EMT+VS and EOF models. Adding spatially-interpolated soil data to the topographic data at Tarrawarra and Nerrigundah decreases model performance and results in worse performance than the EOF method, in which the soil data are not highly weighted. These results suggest that the soil data must have greater spatial detail to be useful to the EMT+VS model. 


\section{ACKNOWLEDGEMENTS}

I would like to thank my advisor Jeffrey Niemann for his guidance throughout this project. I would also like to thank Andrew Jones and committee members Timothy Green and Stephanie Kampf for their insightful comments, Kevin Werbylo and Mike Coleman for their technical support, and Brandon Lehman for his extensive field work conducted for this project. Finally, I would like to thank the Army Research Office Terrestrial Sciences Program for their financial support. 


\section{TABLE OF CONTENTS}

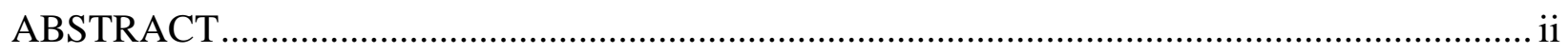

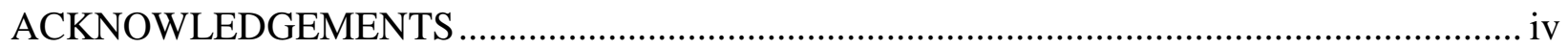

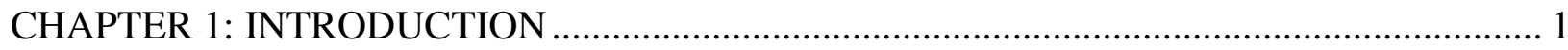

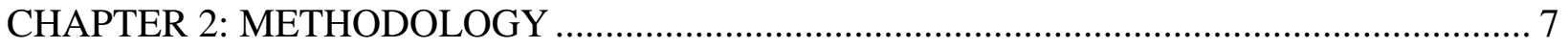

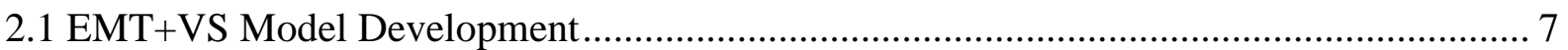

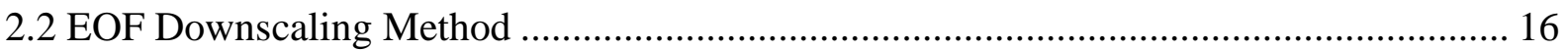

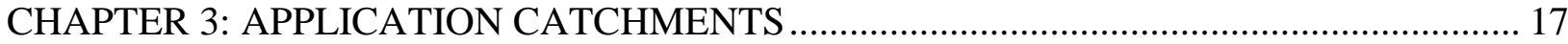

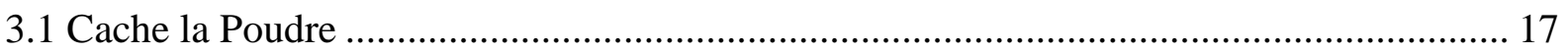

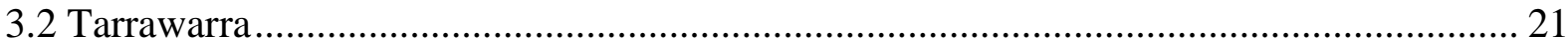

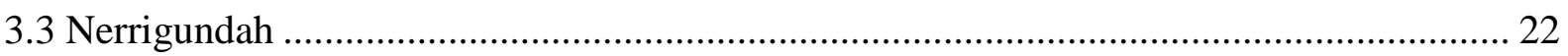

CHAPTER 4: PARAMETER ESTIMATION ................................................................. 24

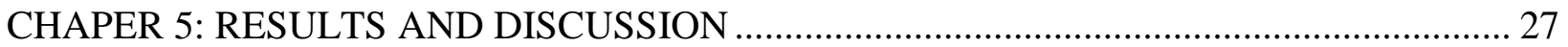

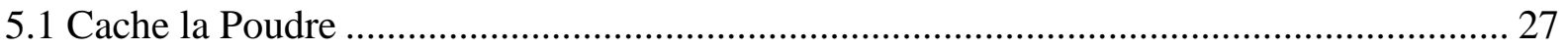

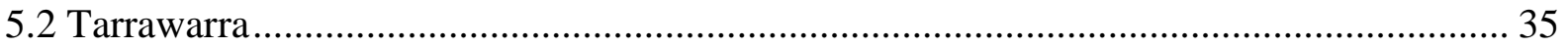

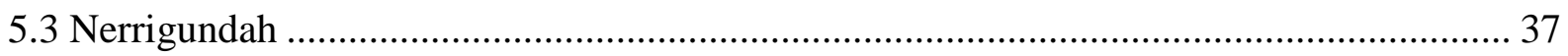

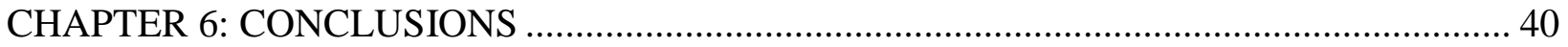

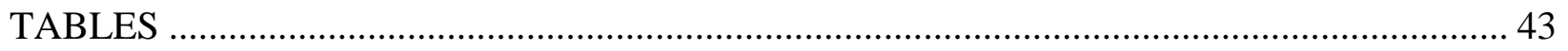

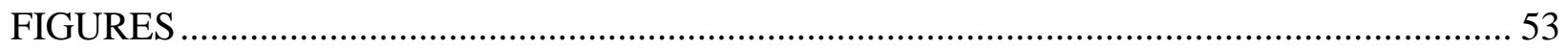

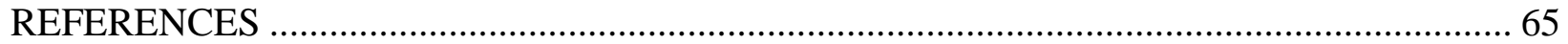




\section{CHAPTER 1: INTRODUCTION}

The understanding of spatially varying soil moisture patterns at a catchment scale is important for many hydrologic applications as it is a key component in the partitioning of precipitation into infiltration, runoff, and evapotranspiration (ET). Estimates of soil moisture are becoming more readily available at coarse to intermediate resolutions. For example, the Advanced Microwave Scanning Radiometer (AMSR-E) provides soil moisture estimates with a $60 \mathrm{~km}$ spatial resolution (Njoku et al., 2003). The Soil Moisture and Ocean Salinity (SMOS) satellites provide soil moisture estimates at $50 \mathrm{~km}$ resolution (Kerr et al., 2001). Passive microwave data from WindSat can be used to estimate soil moisture at $25 \mathrm{~km}$ resolution (Li et al., 2010). The Soil Moisture Active Passive (SMAP) satellite will be able provide soil moisture estimates at spatial resolutions as fine as about $10 \mathrm{~km}$ using $1.2 \mathrm{GHz}$ L-Band radar (Entekhabi et al., 2010). Furthermore, optical and thermal remote-sensing data from MODerate resolution Imaging Spectroradiometer (MODIS) can be used to downscale these coarse resolution estimates to an intermediate resolution $(1 \mathrm{~km})$ (Merlin et al., 2013). Optical and thermal remote-sensing can also be used to estimate intermediate-resolution soil moisture $(500 \mathrm{~m})$ using algorithms such

as the Surface Energy Balance Algorithm for Land (SEBAL) (Bastiaanssen et al., 1998; Scott et al., 2003). Finally, intermediate-resolution soil moisture can be obtained from the Cosmic-ray Soil Moisture Observing System (COSMOS), a ground-based sensor that estimates soil moisture over a $700 \mathrm{~m}$ diameter region when the probe is located a few meters from the ground surface at sea level (Zreda et al., 2008).

Many applications such as water management and agricultural production require finer resolutions $(10-100 \mathrm{~m})$, so methods are needed to further downscale soil moisture estimates. 
To estimate fine-scale variations in soil moisture, high-resolution surrogate data are needed that are strongly associated with these variations. Topographic data are available at the appropriate resolutions and can be an important control on soil moisture. For example, Burt and Butcher (1985) compared soil moisture values with several topographic indices and found that a combined index that includes plan curvature and the ratio of upslope area and slope is best correlated with soil moisture. Brocca et al. (2007) observed that soil moisture is related to slope, elevation, specific contributing area, and distance from the drainage channel. Similar to Burt and Butcher (1985), the strongest correlations occurred during wet conditions (Brocca et al., 2007). Grayson et al. (1997) and Western et al. (1999) found that the dependence of soil moisture on topography can vary through time-a property known as temporal instability. For the Tarrawarra catchment in Australia, lateral water movement controls the soil moisture patterns during wet conditions and specific contributing area is most closely associated with the soil moisture patterns. During dry periods, vertical fluxes control soil moisture and the potential solar radiation index (PSRI) becomes closely associated with the soil moisture patterns.

Several models have been developed to downscale soil moisture based on topographic data. Wilson et al. (2005) developed a model to generate spatiotemporal soil moisture patterns using empirical relationships with topographic attributes that depend on the spatial-average soil moisture. Their model can reproduce temporal instability and performs well for the locations where it was developed, but the empirical relationships are not expected to be widely applicable. Busch et al. (2012) also developed an empirical downscaling method based on Empirical Orthogonal Function (EOF) analysis. This method can also reproduce temporal instability and performs well at the catchments where it was developed, but the model is entirely empirical and thus cannot be applied to regions that are dissimilar to where it was developed (Busch et al., 
2012). Coleman and Niemann (2013) proposed the Equilibrium Moisture from Topography (EMT) model, which also downscales soil moisture based on topographic indices. This method is more physically-based, so the relationships with the topographic indices are determined from conceptual descriptions of the vadose zone processes. This model can also reproduce temporal instability, and it outperforms the EOF method when few soil moisture observations are available for calibration (Werbylo and Niemann, 2014). Although the EMT model includes parameters related to vegetation and soil properties, it does not consider fine-resolution variations of these properties if they occur.

Studies have demonstrated that fine-scale vegetation patterns can also affect catchmentscale soil moisture patterns. For example, Pariente (2002) studied soil moisture under and between shrubs and found downslope and radial soil moisture gradients around the shrubs. During precipitation events, the soil was wetter between shrubs than under shrubs due to interception. During drying periods, the soil was wetter under shrubs than between shrubs in part because the canopy shaded the surface and decreased soil ET (Pariente, 2002). Furthermore, vegetation shading can reduce the amount of water being evaporated from shallow soil (Wallace et al., 1999; Kidron and Gutschick, 2013). Similarly, Lin (2010) found greater soil moisture and less soil evaporation for medium and highly shaded areas than for weakly shaded areas. Rootwater uptake can also affect soil moisture patterns, as top soil layers will dry faster with roots than without (Wallace et al., 1999). Dunkerley (2000) found that infiltration rates decrease further away from a shrub stem while Chen and Wang (2012) found the rate of transpiration increases with leaf area index (LAI). Furthermore, root compensation and hydraulic redistribution can also reduce spatial variations in soil moisture (Guswa, 2012). Vegetation cover (Hupet and Vanclooster, 2002) and seasonal variations in the demand for soil water by 
plants (Gómez-Plaza et al., 2000) can introduce temporal instability in soil moisture patterns. Similarly, Naithani et al. (2013) found that soil moisture and vegetation patterns are very similar from leaf-onset to maturity but different from leaf maturity to senescence. Overall, the factors influencing soil moisture are related to the presence or absence of vegetation (Gómez-Plaza et al., 2001). Vegetation leads to soil moisture patterns that are inversely related to patterns of LAI (He et al., 2014) and is an important control under dry conditions (Mascaro et al., 2010; Baroni et al., 2013).

Spatial patterns of soil moisture also depend upon soil properties including porosity (Famiglietti et al., 1998), hydraulic conductivity (Famiglietti et al., 1998; Martínez García et al., 2014), soil texture (primarily percent clay) (Xu et al., 2008; Takagi and Lin, 2011), and soil depth (Famiglietti et al., 1998; Tromp-van Meerveld and McDonnell, 2006; Takagi and Lin, 2011). The influence of soil properties may be greater during wet conditions (Baroni et al., 2013) and more important relative to topography when the topography is flatter (Zhu and Lin, 2011). Famiglietti et al. (1998) examined the influence of both soil properties and topographic attributes on soil moisture through correlation analysis. They found under wetter conditions, porosity and hydraulic conductivity controlled soil moisture patterns, likely because both have a large impact on water storage and movement. Under dry conditions, topography becomes more important, and relative elevation, cosine of aspect, and clay content influence soil moisture patterns. In a regression analysis, Takagi and Lin (2011) also showed that soil moisture variability for all soil depths considered was explained best by: slope, curvature, topographic wetness index, depth to bedrock, percent clay, and percentage of rock fragments. Finally, Tromp-van Merrveld and McDonnell (2006) observed that differences in soil depth caused variations in soil moisture content, as the total water stored in the soil changes due to soil depth. 
The objective of this thesis is to generalize the EMT model (Coleman and Niemann, 2013) to accept fine-resolution vegetation and soil information if available. It is hypothesized that including the spatial variations in vegetation and soil characteristics will improve the model's ability to downscale soil moisture patterns. The generalization is called the Equilibrium Moisture from Topography, Vegetation, and Soil (EMT+VS) model. The model's representation of vegetation is improved by introducing its primary roles in interception, transpiration, and soil evaporation. In addition, the structure of the model is revised to allow for both vegetation and soil properties to vary at the fine resolution. To test and evaluate performance of the EMT+VS model, it was applied to the Cache la Poudre catchment in Colorado where detailed soil moisture and topographic data, along with litter depth, canopy cover, and soil texture datasets were available. This catchment has substantial spatial variations in vegetation cover. To supplement this primary testing location, the model was also applied to two catchments in Australia (Tarrawarra and Nerrigundah) where detailed soil moisture and topographic data are available along with limited soil data. Although these catchments have relatively homogeneous vegetation (and no vegetation data), they have data for soil properties that are not available at Cache la Poudre. Therefore, the feasibility of using interpolated soil data can also be evaluated at these sites.

The outline of this thesis is as follows. The next chapter ("Methodology") describes how the EMT model was revised to produce the EMT+VS model and briefly describes the EOF downscaling method. The "Application Catchments" chapter describes the three sites where the model was tested and the fine-resolution data that were available at those catchments. Then, the "Parameter Estimation" chapter describes the method used to calibrate the model parameters and the field data used to constrain the allowable ranges. The "Results and Discussion" chapter 
describes the performance of the EMT+VS model at the application catchments and compares it with the EMT model and the EOF method. Finally, the "Conclusions" chapter summarizes the main conclusions from the testing. 
CHAPTER 2: METHODOLOGY

\subsection{EMT+VS Model Development}

The EMT+VS model (like the EMT model) considers the water balance in the hydrologically active layer, which is defined as the depth of soil (beginning at the ground surface) through which lateral flow can potentially occur. In particular, it considers this layer in the land area that is upslope from an edge of a grid cell in a digital elevation model (DEM). It is assumed that soil moisture is uniform with depth within the layer and that the infiltration is balanced by deep drainage (groundwater recharge), lateral flow, and ET. The equilibrium assumption disallows hysteresis in the estimated soil moisture patterns (see Coleman and Niemann (2013) for more detail on this assumption). The water balance can be written as:

$$
\int_{A} F d A=\int_{A} G d A+L+\int_{A} E d A
$$

where $F$ is the infiltration rate, $G$ is the deep drainage, and $E$ is the ET for the fine-resolution grid cells included in the upslope area. The variable $L$ is the lateral outflow across the edge of the DEM cell that defines the upslope area, which is the only location where lateral flow exits in the control volume. The variable $A$ is the area that is upslope from the edge of the DEM cell.

Infiltration $F$ is assumed to be spatially uniform in the EMT model. Interception is known to decrease infiltration (Kozak et al., 2007). Therefore, to include a simple representation of interception in the EMT+VS model, $F$ is modified to be:

$$
F=F_{0}(1-\lambda V)
$$

where $F_{0}$ is the maximum infiltration rate, $V$ is the fractional vegetation cover at the location, and $\lambda(0 \leq \lambda \leq 1)$ is the interception efficiency, a parameter that aims to account for factors that 
influence interception, such as the foliage holding capacity, which depends on vegetation type. If $\lambda=1$, then all rain that falls on the vegetated fraction of the grid cell is assumed to be intercepted and retained by the vegetation, which reduces the infiltration rate for the cell to $F=F_{0}(1-V)$. Interception has been represented in similar ways in other models. For example, the Gridded Surface Subsurface Hydrologic Analysis (GSSHA) model diverts all rainfall to interception until an initial capacity is met. After that time, a constant fraction of the rainfall is lost to interception, similar to Equation (2) (Downer and Ogden, 2004; Downer et al., 2008). The 2-layer Variable Infiltration Capacity (VIC) by Liang et al. (1994) model represents the interception rate as a constant multiplied by the leaf-area index (LAI), which is very similar to the use of $V$ in Equation (2).

Deep drainage $G$ in the EMT+VS model is the same as the EMT model. Specifically, it is assumed to occur with no capillary gradient, so $G$ is equal to the unsaturated vertical hydraulic conductivity, which is determined from the Campbell (1974) equation. Thus,

$$
G=K_{s, v}\left(\frac{\theta}{\phi}\right)^{\gamma_{v}}
$$

where $K_{s, v}$ is the saturated vertical hydraulic conductivity, $\theta$ is the volumetric soil moisture in the hydrologically active layer, $\phi$ is the soil porosity, and $\gamma_{v}$ is the vertical pore disconnectedness index (Campbell, 1974).

Lateral flow also has the same representation in the EMT and EMT+VS models and the equation can be derived from two distinct perspectives (Coleman and Niemann, 2013). In one approach, lateral flow is assumed to occur throughout the entire unsaturated hydrologically active layer. The flow is then derived from Darcy's law, where both the Campbell (1974) equation, which is again used to calculate unsaturated vertical hydraulic conductivity, and the 
soil anisotropy (the ratio of the horizontal to vertical saturated hydraulic conductivities) are multiplied together to calculate the unsaturated horizontal hydraulic conductivity. The horizontal hydraulic gradient is assumed to be a power function of the topographic slope, and the layer thickness is assumed to depend on the topographic curvature, which has been observed for total soil depth (Heimsath et al., 1999). In the second approach, the lateral flow is assumed to occur in a saturated portion of the hydrologically active layer, where the portion is determined by the depth-averaged degree of saturation in the layer. Both approaches lead to the following expression:

$$
L=\delta_{0}\left(\frac{\kappa_{\min }-\kappa}{\kappa_{\min }}\right) c \imath K_{s, v}\left(\frac{\theta}{\phi}\right)^{\gamma_{h}} S^{\varepsilon}
$$

where $\delta_{0}$ is the thickness of the hydrologically active layer where the topographic curvature is zero, $\kappa_{\text {min }}$ is the minimum topographic curvature for which the layer is present, and $\kappa$ is the topographic curvature (Heimsath et al., 1999). Curvature is positive for convergent locations and negative for divergent locations. The variable $c$ is the length of the grid-cell edge and $l$ is the soil anisotropy. The variable $S$ is topographic slope and $\varepsilon(\varepsilon \geq 1)$ is a parameter that relates the horizontal hydraulic gradient to the topographic slope. The variable $\gamma_{h}$ is the horizontal pore disconnectedness if the lateral flow is unsaturated, but it can take smaller values (closer to one) if the lateral flow occurs in a saturated portion of the layer.

The EMT model represents ET using an approach based on Priestley and Taylor (1972), which assumes that the aerodynamic term is a specified fraction of the radiation term in the Penman (1948) equation. In the EMT model, the radiation term is modified to account for the effects of topographic slope and aspect, and actual ET is equal to the potential ET multiplied by a power function of the degree of saturation to account for moisture limitation effects. The same 
approach is used for the EMT+VS model, but the role of vegetation cover is also considered. The revised equation is:

$$
E=E_{p}\left[\eta V+(1-V)^{\mu}\right]\left[\frac{I_{p}}{1+\alpha}\left(\frac{\theta}{\phi}\right)^{\beta_{r}}+\frac{\alpha}{1+\alpha}\left(\frac{\theta}{\phi}\right)^{\beta_{a}}\right]
$$

where $E_{p}$ is the average potential ET, $I_{p}$ is the PSRI (the ratio of the insolation of the topographic surface to that of a horizontal surface at the same latitude and date), $\alpha$ is the ratio of the aerodynamic term to the radiation term (i.e. the Priestly-Taylor coefficient minus one), and $\eta, \mu, \beta_{r}$ and $\beta_{a}$ are vegetation-related parameters. The first and second terms in the second set of square brackets on the right side of Equation (5) are the radiative and aerodynamic components of the ET, respectively, in the Penman equation.

The only new element in Equation (5) is the portion in the first square brackets on the right side. This term is derived by first partitioning $E_{p}$ into potential transpiration and potential evaporation according to fractional vegetation cover $V$. Many other models represent transpiration and/or soil evaporation as functions of LAI (Liang et al., 1994; Wigmosta et al. 1994; Peters-Lidard et al., 1997; Wallace et al., 1999). In the transpiration term $(\eta V), \eta$ is introduced and represents the portion of the total transpiration that is contributed by the modeled soil layer (i.e. the hydrologically active layer). It is expected to depend on the density of roots present in the layer and thus the vegetation type. The transpiration term increases with $V$ because denser vegetation is associated with more root-water uptake and transpiration (Figure 1a). It also increases with larger $\eta$ values because such values indicate that a greater portion of the transpiration is being supplied by the modeled layer. 
In the soil evaporation term $\left((1-V)^{\mu}\right)$, the exponent $\mu$ is introduced because vegetation cover can reduce soil evaporation beyond simply redirecting a portion of the ET to transpiration. For example, canopy cover is expected to reduce wind speed and increase humidity retention near the soil surface. Litter cover can also retain humidity near the soil surface. Ritchie (1972) proposed a detailed model for soil evaporation that was updated to include a shading reduction that is calculated as a function of LAI (Wallace et al., 1999), which has some similarities to the model used here. As $V$ increases, the evaporation term decreases because more of the available energy is used for transpiration (Figure 1b). When $\mu$ is larger, the evaporation term is smaller because the vegetation cover also inhibits soil evaporation. The overall effect of vegetation cover is determined from the sum of the transpiration and evaporation terms (Figure 1c).

The soil moisture is determined from the water balance equation using that same approximate solution strategy that was used to obtain the EMT model. See Coleman and Niemann (2013) for an evaluation of the approximations included in this approach. First, the equations for $F, G, L$, and $E$ from Equations (2) - (5) are substituted into Equation (1), and the following expression is obtained:

$$
F_{0}(1-\lambda V)=\frac{1}{A} \int_{A} K_{s, v}\left(\frac{\theta}{\phi}\right)^{\gamma_{v}} d A+\delta_{0}\left(\frac{\kappa_{\min }-\kappa}{\kappa_{\min }}\right) \frac{c}{A} l K_{s, v}\left(\frac{\theta}{\phi}\right)^{\gamma_{n}} S^{\varepsilon}+\frac{1}{A} \int_{A}\left(\eta V+(1-V)^{\mu}\right) \frac{E_{p}}{(1+\alpha)} I_{p}\left(\frac{\theta}{\phi}\right)^{\beta_{r}} d A+\frac{1}{A} \int_{A}\left(\eta V+(1-V)^{\mu}\right) \frac{E_{p} \alpha}{(1+\alpha)}\left(\frac{\theta}{\phi}\right)^{\beta_{a}} d A
$$

This expression is then approximated by:

$$
F_{0}(1-\lambda V)=K_{s, v}\left(\frac{\theta}{\phi}\right)^{\gamma_{v}}+\delta_{0}\left(\frac{\kappa_{\min }-\kappa}{\kappa_{\min }}\right) \frac{c}{A} l K_{s, v}\left(\frac{\theta}{\phi}\right)^{\gamma_{h}} S^{\varepsilon}+\frac{E_{p}}{(1+\alpha)}\left(\eta V+(1-V)^{\mu}\right) I_{p}\left(\frac{\theta}{\phi}\right)^{\beta_{r}}+\frac{E_{p} \alpha}{(1+\alpha)}\left(\eta V+(1-V)^{\mu}\right)\left(\frac{\theta}{\phi}\right)^{\beta_{a}}
$$

Finally, an explicit equation for $\theta$ is determined from a weighted average of analytical solutions which are derived by assuming that each of the terms on the right side of Equation (7) dominates the determination of soil moisture. The final estimate for the soil moisture is: 


$$
\theta=\frac{w_{G} \theta_{G}+w_{L} \theta_{L}+w_{R} \theta_{R}+w_{A} \theta_{A}}{w_{G}+w_{L}+w_{R}+w_{A}}
$$

where $\theta_{G}, \theta_{L}, \theta_{R}$, and $\theta_{A}$ are the analytical soil moisture equations if deep drainage, lateral flow, radiative ET, and aerodynamic ET dominate in Equation (7), respectively. The variables $w_{G}$, $w_{L}, w_{R}$, and $w_{A}$ control the importance of $\theta_{G}, \theta_{L}, \theta_{R}$, and $\theta_{A}$, respectively, to the final estimate of $\theta$ and are determined from the actual magnitudes of the four terms in Equation (7). The only difference between the solution strategies for the EMT and EMT+VS models is that more variables are allowed to vary spatially in the EMT+VS model.

The solution strategy can be illustrated by considering the deep drainage term. If deep drainage is dominant, then the other terms on the right side of Equation (7) can be neglected, which implies:

$$
\theta_{G}=\phi\left[\frac{F_{0}(1-\lambda V)}{K_{s, v}}\right]^{1 / \gamma_{v}}
$$

Using this equation, the spatial-average soil moisture $\bar{\theta}$ within a catchment (or a coarse resolution grid cell) can be derived as follows:

$$
\bar{\theta}=\frac{1}{A_{c}} \int_{A_{c}} \theta_{G} d A_{c}=\frac{F_{0}^{1 / \gamma_{v}}}{A_{c}} \int_{A_{c}} \phi\left(\frac{1-\lambda V}{K_{s, v}}\right)^{1 / \gamma_{v}} d A_{c}
$$

where $A_{c}$ is the area of the catchment or coarse grid cell. Equation (10) differs from the EMT model not only because vegetation appears in the numerator but also because $K_{s, v}$ and $\phi$ are allowed to vary within $A_{c}$ and thus are kept inside the integral. $F_{0}$ and $\gamma_{v}$ are required to be spatially-constant, which is a necessary assumption to use the solution strategy provided by Coleman and Niemann (2013). The term in the integral is a compound vegetation and soil index 
that introduces spatial variation into the soil moisture estimate, which is termed the deep drainage index (DDI). This pattern of variation is not present in the EMT model:

$$
\mathrm{DDI} \equiv \phi\left(\frac{1-\lambda V}{K_{s, v}}\right)^{1 / \gamma_{v}}
$$

If the spatial-average DDI is denoted $\Psi$, Equation (10) can be rewritten as:

$$
\bar{\theta}=F_{0}^{1 / \gamma_{\nu}} \Psi
$$

Solving this equation for $F_{0}$ and substituting into Equation (9) results in:

$$
\theta_{G}=\bar{\theta} \frac{\mathrm{DDI}}{\Psi}
$$

which is the analytical expression for $\theta_{G}$ that is used in the main equation (Equation (8)).

Using an equivalent solution strategy for the lateral flow term, the model represents $\theta_{L}$ as dependent on a lateral flow index (LFI) according to:

$$
\theta_{L}=\bar{\theta} \frac{\mathrm{LFI}}{\Lambda}
$$

where:

$$
\mathrm{LFI} \equiv \phi\left(\frac{1-\lambda V}{\delta_{0} l K_{s, \mathrm{v}}}\right)^{1 / \gamma_{h}}\left(\frac{A}{c S^{\varepsilon}}\right)^{1 / \gamma_{h}}\left(\frac{\kappa_{\min }}{\kappa_{\min }-\kappa}\right)^{1 / \gamma_{h}}
$$

and $\Lambda$ is the spatial-average of the LFI. To obtain these expressions, only $F_{0}, \gamma_{h}$, and $\varepsilon$ are required to be spatially constant, which deviates from the EMT model. The LFI is a compound topographic, vegetation, and soil index, which introduces another pattern of variation into the soil moisture estimates. An LFI appears in the EMT model, but the only spatially-varying attributes are related to topography. 
Similarly, the model represents $\theta_{R}$ as dependent on a radiative ET index (REI) according

to:

$$
\theta_{R}=\bar{\theta} \frac{\mathrm{REI}}{\Pi}
$$

where:

$$
\mathrm{REI} \equiv \phi\left(\frac{1+\alpha}{E_{p}}\right)^{1 / \beta_{r}}\left(\frac{1}{I_{p}}\right)^{1 / \beta_{r}}\left[\frac{1-\lambda V}{\eta V+(1-V)^{\mu}}\right]^{1 / \beta_{r}}
$$

and $\Pi$ is the spatial-average of the REI. To obtain these expressions, only $F_{0}$ and $\beta_{r}$ are required to be spatially constant. The REI is a compound topographic, vegetation, soil, and climatic index. A similar index appears in the EMT model, but it is called the ET index (ETI) and depends only on topographic attributes.

Finally, the model represents $\theta_{A}$ as dependent on an aerodynamic ET index (AEI) according to:

$$
\theta_{A}=\bar{\theta} \frac{\mathrm{AEI}}{\Omega}
$$

where:

$$
\mathrm{AEI} \equiv \phi\left(\frac{1+\alpha}{E_{p} \alpha}\right)^{1 / \beta_{a}}\left[\frac{1-\lambda V}{\eta V+(1-V)^{\mu}}\right]^{1 / \beta_{a}}
$$

and $\Omega$ denotes the spatial-average of the AEI. To obtain this expression, only $F_{0}$ and $\beta_{a}$ are required to be spatially constant. The AEI is a compound vegetation, soil, and climatic index that introduces spatial variation into the $\theta$ estimate, and it does not appear in the EMT model.

The importance of $\theta_{G}, \theta_{L}, \theta_{R}$, and $\theta_{A}$ to the weighted average is calculated from the magnitude of the associated term in Equation (7). For example, $w_{G}$ is equal to the deep 
drainage term in Equation (7) if $\theta_{G}$ is used in place of $\theta$ (see Coleman and Niemann (2013) for further details). In addition, any coefficients that appear in $w_{G}, w_{L}, w_{R}$, and $w_{A}$ are cancelled because $w_{G}, w_{L}, w_{R}$, and $w_{A}$ appear in both the numerator and denominator of Equation (7). From this approach, one obtains:

$$
\begin{aligned}
& w_{G}=\left(\frac{\bar{\theta}}{\Psi}\right)^{\gamma_{v}} \\
& w_{L}=\left(\frac{\bar{\theta}}{\Lambda}\right)^{\gamma_{h}} \\
& w_{R}=\left(\frac{\bar{\theta}}{\Pi}\right)^{\beta_{r}} \\
& w_{A}=\left(\frac{\bar{\theta}}{\Omega}\right)^{\beta_{a}}
\end{aligned}
$$

and the downscaling method is complete.

To implement the EMT+VS model, certain variables must be provided as fine-resolution maps while other variables are single (spatially-constant) values. The fine-resolution variables include the topographic attributes $\left(A, S, \kappa\right.$, and $\left.I_{p}\right)$, the vegetation characteristics $(V, \lambda, \eta$, and $\mu$ ), soil characteristics $\left(\phi, \imath, K_{s, v}, \delta_{0}\right.$, and $\left.\kappa_{\text {min }}\right)$, and some climate-related characteristics ( $E_{p}$ and $\alpha$ ). Although spatial variability is allowed in these variables, the maps can also indicate that the value is spatially constant (or constant within sub-regions). The output from the EMT+VS model is a map of $\theta$ at the same fine resolution as these inputs. Single constant values must be provided for parameters $\gamma_{v}, \gamma_{h}, \beta_{r}, \beta_{a}, \varepsilon$, and $\bar{\theta}$. Although $F_{0}$ was assumed to be constant, it does not appear in the final model. Note that these parameters could also be 
specified on a coarse grid because each coarse grid cell would be downscaled independently in the EMT+VS model. However, all downscaling is performed using single values for these attributes, including $\bar{\theta}$, in this paper.

\subsection{EOF Downscaling Method}

The EMT+VS model will be evaluated in part by comparing its results to those from an empirical downscaling method based on EOF analysis (Busch et al., 2012). The EOF method requires a calibration soil moisture dataset with observations at the same collection of locations on multiple dates. This soil moisture dataset is then decomposed into: (1) the spatial-average soil moisture on each date, (2) time-invariant spatial patterns of covariation (the EOFs), and (3) expansion coefficients (ECs), which are time series that indicate the importance of each EOF to the soil moisture pattern on each date. Together, these three components can be used to perfectly reconstruct the space-time soil moisture dataset. However, to allow the method to be applied for dates and locations without soil moisture observations, Busch et al. (2012) discarded the EOFs that are not statistically significant. Then, the remaining EOF patterns were estimated from stepwise multiple linear regressions against topographic indices, and the ECs were estimated from segmented-linear relationships with the spatial-average soil moisture (see Busch et al., 2012 for more details). In the end, the method can estimate the soil moisture pattern from a supplied spatial-average soil moisture and fine-resolution topographic data. Although Busch et al. (2012) estimated the EOFs using only fine-resolution topographic attributes, the method can be expanded to include fine-resolution vegetation and/or soil characteristics if they are available. In the present study, the EOF method is supplied with the different types of fine-resolution inputs to allow for fair comparisons to different EMT+VS model scenarios. 


\section{CHAPTER 3: APPLICATION CATCHMENTS}

The EMT+VS model is applied to three catchments with extensive soil moisture and topographic data available. The primary test catchment is the Cache la Poudre, which was selected because of its substantial variations in vegetation cover. Extensive vegetation (litter depth and canopy cover) data and soil texture data were also available. Supplemental testing of the model is performed using the Tarrawarra and Nerrigundah catchments. Although these catchments have relatively homogeneous vegetation (and no vegetation data), they have data for soil properties that are not available at Cache la Poudre including soil depth. The following sections describe each catchment and the fine-resolution data that are available for use in the EMT+VS model. Table 1 provides a summary characteristics and available data for each application catchment.

\subsection{Cache la Poudre}

The Cache la Poudre catchment is located near Rustic, Colorado and is in the Southern Rockies ecoregion (Omernik, 1987; Traff, 2013). The catchment area is approximately 8.0 ha, and the climate is semi-arid with $415 \mathrm{~mm}$ mean annual precipitation (Lehman and Niemann, 2008). It has aspect-dependent vegetation with a coniferous forest with sparse deciduous shrub understory on the north-facing slope (NFS) and shrubland with sparse coniferous trees on the south-facing slope (SFS) (Figure 2a). The NFS is dominated by Ponderosa Pine (Pinus ponderosa), while Douglas-fir (Pseudotsuga menziesii), Rocky Mountain Juniper (Juniperous scopulorum), and Common Juniper (Juniperus communes) are also present. The dominant understory shrub is Mountain Mahogany (Cercocarpus montanus) and Antelope Bitterbrush (Purshia tridentate). The SFS consists primarily of Mountain Mahogany and Antelope 
Bitterbrush shrubs with Mountain Big Sagebrush (Artemisia tridentate subs. vaseyana) found at the lowest elevations. A few Ponderosa Pine and Rocky Mountain Juniper trees are also found on the SFS (Lehman and Niemann, 2008).

Soil moisture data were previously collected (Coleman and Niemann, 2012) for the top 5 $\mathrm{cm}$ of the soil using time domain reflectometry (TDR) on the $15 \mathrm{~m}$ grid, which is shown in Figure 2. Soil moisture was measured on 9 dates between April 22, 2008 and June 24, 2008, and the spatial-average soil moisture ranged from 0.04 to 0.19 . Only the 350 locations that were measured on all nine dates are used in the present study. Elevation data were also available on the same $15 \mathrm{~m}$ grid (Figure 2b) (Lehman and Niemann, 2008). The average elevation is approximately $2195 \mathrm{~m}$ and total relief is approximately $115 \mathrm{~m}$.

The vegetation cover is characterized by available litter depth $\left(L_{d}\right)$ and canopy cover $\left(C_{c}\right)$ on the $15 \mathrm{~m}$ grid collected and analyzed by Lehman and Niemann (2008) in Fall 2008. Litter depth was measured manually, and the value at each grid point (Figure 3a) is the average of multiple measurements within $10 \mathrm{~cm}$ of the grid point. The values range from 0 to $15 \mathrm{~cm}$ with an average of $3 \mathrm{~cm}$. Canopy cover was determined from photographs that were taken vertically upward from the ground surface at each of the grid points. A 3.2 megapixel multispectral digital camera (Tetracam Agriculture Digital Camera) was used, which has view angles of $31.6^{\circ}$ and 39.4 $4^{\circ}$ The images were analyzed using Tetracam's PixelWrench software. The vegetation and sky pixels in the images were distinguished using the red and infrared reflectances. The fraction of the pixels that are vegetation was used for $C_{c}$ (Figure $3 \mathrm{~b}$ ). The canopy cover values range from 0 to 0.90 with an average value of 0.39 . Note that this method for determining $C_{c}$ differs from LAI because LAI accounts for multiple layers of vegetation cover and thus can have values above one (Carlson and Ripley, 1997; Asner et al., 2003; Naithani et al., 2013). As expected 
from Figure 3, both $L_{d}$ and $C_{c}$ depend on the hillslope orientation. The correlations of $L_{d}$ and $C_{c}$ with the cosine of topographic aspect are 0.47 and 0.62 , respectively.

The $L_{d}$ and $C_{c}$ measurements were combined to determine the fractional vegetation cover $V$ for the EMT+VS model. Both types of measurements are used because both canopy and litter cover can intercept rainfall (Gerrits and Savenije, 2011) and reduce soil evaporation (by increasing shading, reducing wind speed, and increasing humidity at the soil surface). Although $C_{c}$ is expected to determine the portion of potential ET that is used for transpiration, both $C_{c}$ and $L_{d}$ are expected to be correlated with root density. Thus, overall both variables are relevant when determining $V$.

To determine $V, L_{d}$ is first transformed into a fractional litter cover $L_{c}\left(0 \leq L_{c} \leq 1\right)$ by the following equation:

$$
L_{c}=\tanh \left(\frac{L_{d}}{\zeta}\right)
$$

where $\zeta$ is a reference litter depth $(\zeta>0)$ and a calibrated parameter. This transformation is necessary because litter depth is not bounded by zero and one. A hyperbolic tangent is used in Equation (24), but other sigmoid functions produce similar results when used in the EMT+VS model. $V$ is then found by assuming that the canopy and litter cover occur independently within a fine-resolution grid cell, which implies:

$$
V=L_{c}+C_{c}-L_{c} C_{c}
$$

Figure $3 \mathrm{c}$ shows $V$ as calculated by this approach. Alternative methods to estimate $V$ from $L_{c}$ and $C_{c}$ were considered and tend to produce similar results because a strong relationship is 
observed between $L_{d}$ and $C_{c}$ ( $L_{d}$ is well described by an exponential function of $C_{c}$ ). However, formulations that rely more on $L_{d}$ than $C_{c}$ slightly improve the performance of the EMT+VS model.

The soil texture in the top $5 \mathrm{~cm}$ was available from soil samples collected at every second point on the $15 \mathrm{~m}$ grid (resulting in 86 points on a $30 \mathrm{~m}$ grid, Figure 2) (Lehman and Niemann, 2008). Fractions of coarse gravel $(4.75-12.5 \mathrm{~mm})$, fine gravel $(2-4.75 \mathrm{~mm})$, coarse sand $(0.6-2$ $\mathrm{mm})$, and fine sand $(0.05-0.6 \mathrm{~mm})$ were available from sieve analysis. Fractions of silt $(0.02-0.6$ $\mathrm{mm})$ and clay $(<0.02 \mathrm{~mm})$ were available from the standard hydrometer method (Figure 4a-c). A cumulative distribution function was then determined for each grid point to determine the $10^{\text {th }}$ percentile (D10), 20 $0^{\text {th }}$ percentile (D20), and $50^{\text {th }}$ percentile (D50) of grain diameter. Large spatial variations occur in the percent sand, silt, and clay, but little organization is observed in Figure 4. However, silt is more abundant on the NFS, and exhibits a correlation with cosine of aspect of 0.18 .

Maps of saturated hydraulic conductivity and porosity were determined from the soil texture data using pedotransfer functions developed by Cosby (1984). Both functions were developed from samples that included A horizon soils, sandy loams, and topography with slopes up to $55 \%$. Thus, it is expected to be appropriate for this catchment. However, the catchment includes an abundance of very large grain sizes, which might diverge from the datasets used to develop these functions. The resulting conductivity values range from 936 to $1845 \mathrm{~mm} /$ day with an average of $1356 \mathrm{~mm} /$ day, and like the soil texture data, exhibit little organization (Figure 4d). Because information for anisotropy is not available, the conductivity values are used for $K_{s, v}$ in the model and a spatially-constant anisotropy $\imath$ is calibrated to determine the horizontal saturated 
hydraulic conductivity (see next chapter). The resulting porosity values range from 0.38 to 0.41 $\left(\mathrm{m}^{3} / \mathrm{m}^{3}\right)$ with an average of $0.39\left(\mathrm{~m}^{3} / \mathrm{m}^{3}\right)$ and also exhibits little spatial organization (Figure $4 \mathrm{e}$ ).

\subsection{Tarrawarra}

The Tarrawarra catchment is located in southern Victoria, Australia. It is approximately 10.5 ha in area and has a temperate climate with a mean annual precipitation of $820 \mathrm{~mm}$. Soil moisture data are available on a 10 by $20 \mathrm{~m}$ grid for 13 dates from September 27, 1995 to November 29, 1996 (Western and Grayson, 1998). The data were collected using a TDR in the top $30 \mathrm{~cm}$ of the soil (Western et al., 1999). Only the 454 locations that are available on all 13 dates are used for in this study. Topographic data are also available on a $5 \mathrm{~m}$ grid. The required topographical attributes $\left(S, A, \kappa\right.$, and $\left.I_{p}\right)$ were determined based on this DEM and then filtered to include only the cells with soil moisture measurements (Figure 5a).

Field-saturated hydraulic conductivity values are available from well permeameter tests at 42 locations (Western and Grayson, 1998). Some of these locations occur within the same soil moisture grid cells. In such cases, the observations were averaged to determine a single value for the grid cell, which results in 32 cells with data. To obtain a complete hydraulic conductivity map, the data were interpolated using the linear inverse weighted distance (IWD) method using a search radius of 3 points (Figure $5 b$ ). The resulting map of conductivity exhibits higher values on the NFS (Figure 5b). Information about anisotropy is not available, so like Cache la Poudre, the conductivity values are used for $K_{s, v}$, and $\imath$ is calibrated to determine the horizontal saturated hydraulic conductivity.

The EMT+VS model calculates the thickness of the hydrologically active layer as a linear function of topographic curvature, and two variables are required to determine that linear relationship ( $\delta_{0}$ and $\kappa_{\min }$ ). For Tarrawarra, the A horizon (20 to $35 \mathrm{~cm}$ deep) is selected as the 
hydrologically active soil layer, as the top $30 \mathrm{~cm}$ of soil accounts for approximately half of moisture storage of the soil profile (Western et al., 1999). The thickness of the A horizon is available at 116 points on a 20 by $40 \mathrm{~m}$ grid with a $5 \mathrm{~m}$ offset from the soil moisture measurements (Western and Grayson, 1998). These observations were plotted against the curvature, and two distinct relationships are observed where the curvature is positive and negative. Thus, this catchment was divided into two soil groups based on the sign of the curvature and distinct values of $\delta_{0}$ and $\kappa_{\text {min }}$ that were estimated from the data in those two groups.

\subsection{Nerrigundah}

The Nerrigundah catchment is located northwest of Dungog in New South Wales, Australia. The catchment area is approximately 6.0 ha and has a temperate climate with a mean annual precipitation of about $1000 \mathrm{~mm}$ (Walker, 1999; Walker et al., 2001). Soil moisture for the top $15 \mathrm{~cm}$ is available on a $20 \mathrm{~m}$ grid on 12 dates from August 27, 1997 to September 22, 1997. Only the 238 locations that are available on all 12 dates are used here. Topographic data are also available from a $20 \mathrm{~m}$ DEM (Figure 6a).

Saturated hydraulic conductivity and porosity are available at 19 locations throughout the catchment (Walker, 1999; Walker et al., 2001). Saturated hydraulic conductivities were determined from Kozeny-Carmen, Guelph permeameter, and double-ring infiltrometer tests. The double-ring infiltrometer test data were used for EMT+VS model testing as they were most representative of the hydrologically active layer. Depths to the bottom of each of the A1, A2, B1, and B2 horizons were also available. Porosities, determined from bulk density measurements, and soil texture data were available for all horizons. For Nerrigundah, the hydrologically active layer is assumed to extend to the bottom of the B1 horizon because the 
saturated hydraulic conductivity decreases substantially from the B1 to the B2 horizon. The porosity for the hydrologically active layer was estimated from a weighted average of the porosities from the included horizons. Similar to Tarrawarra, when more than one conductivity or porosity value is available in a grid cell, those values were averaged, which results in 17 cells with conductivity data and 15 cells with porosity data. To obtain complete maps, interpolations were performed using the same method that was used with Tarrawarra data. The interpolated conductivity map has higher values on the upper portions of the NFS and SFS (Figure 6b), while the porosity tends to be larger in the western portion of the catchment (Figure 6c). Similar to the other catchments, the conductivity values are used for $K_{s, v}$ in the EMT+VS model, and $\imath$ is calibrated to determine the horizontal saturated hydraulic conductivity. 


\section{CHAPTER 4: PARAMETER ESTIMATION}

This chapter describes how the remaining variables were estimated for the EMT+VS model. The general procedure is as follows. When a value is known for a catchment, that value is used in the model. Otherwise, the value is calibrated to maximize the average Nash Sutcliffe Coefficient of Efficiency (NSCE) (Nash and Sutcliffe, 1970) for all dates in the soil moisture dataset (NSCE is equal to 1 minus the ratio of the squared error to the variance). For a calibrated parameter, any available observations are used to determine the allowable range. If no local observations are available, the calibration ranges are based on broadly applicable ranges from Coleman and Niemann (2013) or from theoretical bounds. The specified values and calibration ranges for all three test catchments are provided in Table 2.

The climate-related variables include $E_{p}$ and $\alpha$, which were both directly specified. The $E_{p}$ value for Cache la Poudre was calculated from the Priestly-Taylor equation by Coleman and Niemann (2013), the $E_{p}$ value for Tarrawarra was acquired from literature (Western and Grayson, 1998), and the $E_{p}$ value for Nerrigunah was estimated from class A pan evaporation (Walker, 1999; Walker et al., 2001) using a pan coefficient of approximately 0.65. The variable $\alpha$ was set to 0.26 for all catchments under the assumption that the Priestly-Taylor coefficient is 1.26 (Eichinger et al., 1996).

No vegetation cover data are available for Tarrawarra or Nerrigundah. In both cases, photographs and available information suggest that the vegetation is relatively homogeneous grass (Western and Grayson, 1998; Walker, 1999; Walker et al., 2001). Thus, $V=1$ is assumed for all locations in both catchments. For all catchments, the vegetation-related parameters $(\lambda$, 
$\eta, \mu, \beta_{r}$, and $\beta_{a}$ ) were calibrated. The ET exponents $\beta_{r}$ and $\beta_{a}$ were calibrated within broadly applicable ranges from Coleman and Niemann (2013). The interception efficiency $\lambda$ and the portion of the total transpiration that is contributed by the modeled soil layer $\eta$ have theoretical lower and upper bounds at 0 and 1 which were used to define their calibration ranges. The soil evaporation reduction $\mu$ has theoretical upper and lower bounds at 1 and 3 . The reference litter depth $\zeta$ is required only at Cache la Poudre to transform litter depth measurements into fractional litter cover. Its allowable range has a lower limit of $0.001 \mathrm{~m}$ to avoid a zero occurring in its denominator and has no upper limit.

Where fine-resolution datasets are unavailable, the soil hydraulic properties $\left(\phi, K_{s, v}, \imath\right.$, $\gamma_{h}, \gamma_{v}$, and $\varepsilon$ ) were calibrated. The porosities $\phi$ for Tarrawarra are calibrated within the broad ranges from Coleman and Niemann (2013) because no bulk density or soil texture measurements are available. In some model scenarios for Cache la Poudre and Nerrigundah, porosity $\phi$ is assumed to be spatially-constant, in which case its calibration range is determined from the ranges of $\phi$ measurements. Similarly, in tests where $K_{s, v}$ is assumed to be spatially-constant, the calibration range is determined from the ranges of conductivity values. The anisotropy $\imath$ is allowed to range from 1 to 100 for all catchments (Fitts, 2002). The allowable range for $\gamma_{v}$ at Tarrawarra is determined from Coleman and Niemann (2013) because no soil texture data are available. The allowable ranges for $\gamma_{v}$ at Cache la Poudre and Nerrigundah are determined from pedotransfer functions that rely on the available soil texture data (Cosby et al., 1984). The upper bounds for $\gamma_{h}$ are the same as those for $\gamma_{v}$ at the same catchment, but the lower bound is set to one to allow for saturated lateral flow (Coleman and Niemann, 2013). The calibration also 
requires $\gamma_{h}<\gamma_{v}$ similar to Coleman and Niemann (2013). Finally, the range for $\varepsilon$, which relates the hydraulic gradient to the topographic slope, is also from Coleman and Niemann (2013) because no catchment-specific observations are available for this parameter.

The EMT+VS model calculates the thickness of the hydrologically active layer using two variables $\left(\delta_{0}\right.$ and $\left.\kappa_{\min }\right)$. No soil or horizon depths are available at Cache la Poudre, so the $\delta_{0}$ value and the calibration range for $\kappa_{\text {min }}$ proposed by Coleman and Niemann (2013) were used. For Tarrawarra and Nerrigundah, in tests where $\delta_{0}$ and $\kappa_{\text {min }}$ are assumed to be spatially-constant, a linear regression was performed with the available data to estimate the layer thickness as a function of curvature. $\delta_{0}$, which is the thickness where curvature is zero, could be reliably estimated for both catchments because multiple observations have curvature values close to zero. Due to the large number of data points and wide range of $\kappa$ values available at Tarrawarra, $\kappa_{\text {min }}$ could be also reliably estimated from the regression line. However, the regression line at Nerrigundah must be extrapolated to estimate $\kappa_{\text {min }}$, so $\kappa_{\min }$ was instead calibrated within the same broad range as Cache la Poudre. 


\section{CHAPER 5: RESULTS AND DISCUSSION}

This chapter describes the results when the EMT+VS model is applied to the test catchments and compares those results to both the EMT model and the EOF method proposed by Busch et al. (2012). To apply the EOF method, the same collection of topographic attributes that were used by Busch et al. (2012) are considered. For Cache la Poudre, the litter depth and canopy cover data are supplied to the EOF method for cases when vegetation data are considered. Similarly, percent sand, percent silt, percent clay, D10, D20, D50, saturated hydraulic conductivity, and porosity are supplied to the EOF method when soil properties are considered. For Tarrawarra, the fine-resolution conductivity, and $\delta_{0}$ and $\kappa_{\text {min }}$ values are supplied to the method when soil variables are considered. Finally, for Nerrigundah, the fine-resolution conductivity and porosity values are supplied to the method when soil variables are considered.

\subsection{Cache la Poudre}

The EMT+VS model is first applied to Cache la Poudre at a $15 \mathrm{~m}$ resolution by including the fine-resolution vegetation data along with the topographic data that is already used in the EMT model. In this scenario, $K_{s, v}$ is calibrated rather than using the data from the $30 \mathrm{~m}$ grid. Calibrated parameters and spatially-constant variables for this test can be seen in Table 3 . Figure 7 shows examples of the observed and downscaled soil moisture patterns for Cache la Poudre. The date was selected because the observed pattern is typical for the dataset. The top row shows the results when only fine-resolution topographic data are used for downscaling, and the bottom row shows the results when both fine-resolution topographic and vegetation data are used. The observed soil moisture pattern (Figure 7a) exhibits wetter conditions on the NFS than the SFS, and the western part of the catchment is wetter than the eastern part of the catchment. 
Substantial local variations in soil moisture are also observed. When only topographic data are used, the downscaled pattern from the EOF method (Figure 7b) is more realistic than the pattern from the EMT model (Figure 7c) because it better represents the wetter conditions in the western part of the catchment. Both downscaled patterns exhibit less spatial variation than the observed soil moisture pattern. When both topographic and vegetation data are included, the pattern from the EOF method (Figure 7e) remains nearly unchanged. The EOF method with topography data downscales primarily with $I_{p}$ while the EOF method with topography and vegetation downscales with $I_{p}$ and both vegetation data. Because $I_{p}$ and vegetation data are highly correlated, little change between the two cases is expected. In contrast, the soil moisture pattern from the EMT+VS model (Figure 7f) is substantially different than the pattern from the EMT model (Figure 7c), and it is more realistic because it captures the wetter conditions in the western part of the catchment and it captures some of the local variability (speckle) in the soil moisture, with the greatest improvement seen on the SFS.

The top half of Table $4(15 \mathrm{~m}$ grid) quantifies the average performance of the downscaling methods for this scenario. The NSCE, root mean square error (RMSE), and mean relative error (MRE) were calculated for each date in the dataset, and the table provides the average values for these metrics. The results confirm that the example shown in Figure 7 is representative of the dataset. Specifically, when only topographic data are used, the EOF method outperforms the EMT model. When topographic and vegetation data are used, the EMT+VS model outperforms both the EOF method and the EMT model. For example, when only topographic data are used in the EMT model the average NSCE is 0.080. When topographic and vegetation data are used in the EMT+VS model, the average NSCE is 0.134. This improvement suggests that vegetation plays a significant role in determining the soil 
moisture patterns at this catchment and that the EMT+VS model captures some of that role. The improvement in performance of the EMT+VS model to the EOF method also suggests that the representation of vegetation in EMT+VS model is better than the linear dependence assumption of the EOF method.

As seen from NSCE results, the EMT+VS model is unable to fully capture the observed patterns. Although the theoretical maximum NSCE value is 1, results from Busch et al. (2012) suggest that a likely maximum possible NSCE when it is calculated in this way is about 0.60 because the remaining variation in soil moisture datasets is uncorrelated noise (i.e. the EOFs are not statistically significant patterns of variation). As seen from Table 4, the EMT+VS model performance remains well below this estimated maximum performance and this variation might be largely due to measurement errors. Similarly, the RMSE value for the EMT+VS model is about 0.030 , which is a little larger than measurement errors that are commonly reported for TDR data, approximately 0.01 (Hignett and Evett, 2008). The MRE values are high, greater than 0.4 , because the observed soil moisture values are often low compared to estimated soil moisture values. Thus, the errors are large relative to these small numbers.

Some of the estimation error is likely inherited from assumptions and simplifications used to derive the EMT model. First, the equilibrium assumption means that the model can produce only one soil moisture pattern for a given spatial-average soil moisture. However, the observed soil moisture patterns can exhibit differences when the spatial-average soil moisture is nearly identical. Second, the approximations that are used to produce an explicit soil moisture equation produce some distortions in the estimated soil moisture patterns (see Coleman and Niemann, 2012). Third, the process representations are conceptual, assume constant soil moisture with depth, and infer hydraulic properties from topographic attributes. Fourth, the 
values of model inputs and parameters may include errors. For example, $E_{p}$ was also treated as constant in time based on previous EMT model testing and the equilibrium assumption. The variable $\alpha$ was also assumed to be the same for all catchments, but some research suggests that this value might change with climate (Cristea et al., 2012).

Other errors are introduced by the simplified representation of vegetation in the EMT+VS model. The model does not include a permanent wilting point, which could introduce errors in the soil moisture patterns for very dry conditions. The model assumes that a fixed portion of transpiration occurs from the hydrologically active layer, but this portion likely varies depending upon the availability of moisture at different depths. The vegetation cover and vegetation parameters are all treated as constant through time, so any changes with season are neglected. In addition, the vegetation parameters are considered spatially constant even though the type of vegetation varies spatially in the catchment.

Finally, some error is inherent in comparing EMT+VS estimates to TDR measurements due to differences in their spatial scales. The TDR measures soil moisture over a range of a few centimeters, while the EMT+VS model estimates soil moisture patterns at the resolution of the supplied fine-resolution datasets (15 $\mathrm{m}$ in this case).

NSCE can also be calculated by considering the entire space-time dataset at once. When calculated in this manner, the NSCE evaluates the spatial and temporal variation that is reproduced by the application of the downscaling method. When calculated in this way, the NSCE is 0.788 for the EMT+VS model. The method is very effective at capturing temporal variability in part because the spatial-average soil moisture is provided as an input. Nonetheless, the high value indicates that estimates from the EMT+VS model are accurate enough to be useful for a variety of applications. 
The EMT+VS model's ability to reproduce the statistical properties of the soil moisture patterns can also be evaluated. The spatial-average is reproduced due to the mathematical structure of the model. Thus, the bias on each date is zero. Table 5 shows the average, maximum, and minimum standard deviations for the observed and estimated patterns of all dates in the dataset. Overall, the EMT+VS patterns have much smaller standard deviations than the observed patterns and slightly smaller values than the EOF estimates. However, the standard deviation for the EMT+VS model is more realistic than the EMT model.

Additional tests were run to determine the particular role of vegetation that is responsible for the improved performance of the EMT+VS model relative to the EMT model. First, the influence of interception was evaluated by modifying the EMT+VS model to only include the interception term. This test produced an average NSCE that is nearly the same as the EMT model. Because the observed soil moisture patterns are relatively dry, interception is not expected to play a large role. The importance of root-water uptake (and transpiration) was then determined by examining the calibrated $\eta$ value. This value is 0.06 , meaning only $6 \%$ of the transpiration is derived from the hydrologically active layer. This low value is expected because the layer is selected to be very small $(5 \mathrm{~cm})$ and because the vegetation is primarily shrubs and trees. Together these results suggest that the reduction of soil evaporation (due to increased shading and humidity and reduced wind speed) is the dominant mechanism by which vegetation affects soil moisture at the Cache la Poudre. The importance of soil evaporation at shallow depths has also been observed for another semi-arid shrubland (Kurc and Small, 2004). These results also imply that the representations of interception and transpiration in the EMT+VS model are not well tested based on this catchment. 
Figure 8 shows the weights that are used in the main equation to estimate $\theta$ for the EMT and EMT+VS models for this scenario. Weights are defined as the importance of each process (e.x. $w_{G}$ ) divided by the sum of importance terms for all processes. Both models suggest that lateral flow plays little role in determining the soil moisture patterns across the range of $\bar{\theta}$ values in the dataset, which describes a catchment with relatively dry soils. However, the EMT model exhibits an increase in the lateral flow weight for very low $\bar{\theta}$ values. That behavior is not realistic because transmission of water in the soil becomes more efficient as the soil approaches saturation, and lateral flow is generally considered to be more important under wet rather than dry conditions (Grayson et al., 1997; Western et al., 1999). In contrast, the lateral flow weight in the EMT+VS model is always zero, which is more realistic for this dataset. The EMT+VS model has smaller values of the radiative ET weight and larger values of the aerodynamic ET weight than the EMT model. The reduction in the radiative ET weight suggests that some of the soil moisture variation that was attributed to variations of insolation (i.e. radiative ET) in the EMT model is now being explained also by variations in vegetation cover, which affect both the radiative and aerodynamic ET. Because the vegetation cover is highly dependent on hillslope orientation, vegetation variations could easily be misinterpreted as insolation variations in a model that only considers topography. Both models suggest that deep drainage dominates when $\bar{\theta}$ becomes large.

The patterns of variation that are used to estimate the soil moisture in the EMT and EMT+VS models are shown in Figure 9. The DDI, which is not present in the EMT model, depends on vegetation cover because of vegetation's role in interception. The DDI has larger values on the SFS where the vegetation is sparse, which reduces interception. Thus, under wet conditions when deep drainage dominates, the EMT+VS model produces patterns that are wetter 
on the SFS than NFS, while the EMT model produces uniform soil moisture. The LFI also depends on vegetation cover, but this index mainly reflects the valley configuration and is similar to the LFI in the EMT model. Recall that the LFI is not used in the EMT+VS model because $w_{L}=0$. The REI pattern in the EMT+VS model is analogous to the ETI pattern in the EMT model. Both patterns have higher values on the NFS because that slope receives less insolation ( $I_{p}$ is lower). However, the REI also incorporates shading and retention of humidity by vegetation, which introduces more local variability in the REI pattern than the ETI pattern. The fourth pattern of variation in the EMT+VS model is the AEI, which is not present in the EMT model and depends only on the vegetation cover. It also has larger values on the NFS and the western portion of the catchment where the vegetation cover is thicker, and it will tend to promote higher soil moisture on that slope under dry conditions when it is important.

The next two scenarios evaluate the EMT+VS model's use of fine-resolution $K_{s, v}$ and $\phi$ data. For the second scenario, the EMT+VS model is applied at a $30 \mathrm{~m}$ resolution where both fine-resolution vegetation and soil $\left(K_{s, v}\right)$ data are available. Calibrated parameters and spatiallyconstant variables for this test can be seen in Table 6. Figure 10 compares the downscaled soil moisture pattern to the observed pattern for an example date. The top row of Figure 10 uses only topographic and vegetation data, and these patterns are produced using the same approach that was used for the $15 \mathrm{~m}$ grid. The middle row shows the results when $K_{s, v}$ data are added to the downscaling methods. The results of the EOF method change slightly with the addition of the soil data (comparing Figure $10 \mathrm{~b}$ to $10 \mathrm{e}$ ), but the results of the EMT+VS model are nearly identical in both cases. Most soil moisture patterns in this dataset represent dry conditions and are controlled by the REI and AEI, which do not depend on $K_{s, v}$. Thus, available soil 
information is only beneficial for wet conditions when deep drainage is important. Although a wetter day $(\bar{\theta}=0.15)$ is shown (Figure 10$)$, the catchment is still relatively dry and therefore vegetation plays a larger role in determining soil moisture patterns.

The bottom half of Table $4(30 \mathrm{~m}$ grid) evaluates the average performance of the EMT+VS model when only topography, both topography and vegetation, and topography, vegetation, and soil data are used. The addition of fine-resolution vegetation data in the downscaling method improves the average performance similar to what was observed at the 15 m resolution. However, including the $K_{s, v}$ data as well makes very little difference in the EMT+VS model performance. This insensitivity partly occurs because only two dates are wet enough $(\bar{\theta}=0.19)$ for deep drainage and thus $K_{s, v}$ to be important. Thus, the performance on most dates is unchanged. When the soil data are included, the performance of the EMT+VS model is again below that of the EOF method. This result might suggest that the simplified representations of the hydrologic processes in the EMT+VS model makes it difficult for it to benefit from detailed representations of the soil properties. It might also indicate that some roles of soil variability are not being captured in the EMT+VS model (for example, by use of the simplified Campbell equation). The use of a pedotransfer function to estimate $K_{s, v}$ is also expected to introduce errors, but the EOF method should also be sensitive to these errors. It should be noted that one fewer parameter $\left(K_{s, v}\right)$ is calibrated when the soil data are provided in the EMT+VS model. In contrast, the EOF method continues to calibrate its dependence on the provided spatial pattern. When $K_{s, v}$ data are included in the EMT+VS model, the space-time NSCE is 0.805 , which indicates good overall performance. 
The final scenario at Cache la Poudre applied the EMT+VS model at a $30 \mathrm{~m}$ resolution where fine-resolution vegetation and soil $\left(K_{s, v}\right.$ and $\left.\phi\right)$ data are available. The bottom row of Figure 10 shows results when both $K_{s, v}$ and $\phi$ data are added to the downscaling methods. The results of the EOF method are identical between the soil cases as the EOF chooses not use $\phi$ data. The EMT+VS model between soil cases shows some grid cells as being estimated slightly wetter when $\phi$ data are included which correspond to areas of higher $\phi$ values, suggesting $\phi$ is being correctly estimated at the catchment and improving soil moisture estimation.

The last two rows of Table 4 evaluates the performance of the EMT+VS model when topography, vegetation, soil ( $K_{s, v}$, and $\phi$ ) data are used. The addition of both soil data does not change EOF method performance from when only $K_{s, v}$ data are used. When the soil data are included in the EMT+VS model, the space-time space-time NSCE of 0.807. These slight increases in performance suggest that when porosity data are included, they can improve the soil moisture estimates. Again, neither the EMT+VS model or EOF method produce the variance of observed conditions as seen in Table 5.

\subsection{Tarrawarra}

At Tarrawarra, the EMT+VS model's use of fine-resolution data for both $K_{s, v}$ and the soil depth parameters $\left(\delta_{0}\right.$ and $\kappa_{\text {min }}$ ) is evaluated. The first application of the model includes the fine-resolution $K_{s, v}$ data. The top row in Figure 11 shows example downscaled patterns that are produced when only topographic data are used, and the middle row shows the results when the $K_{s, v}$ data are included. Calibrated parameters and spatially-constant variables for this test can be seen in Table 7. The observed soil moisture pattern (Figures 11a) has valley bottoms that are 
wetter than the hillslopes. In addition, the NFS is drier than the SFS. When only fine-resolution topographic data are used in the EOF method (Figure 11b), the downscaled pattern exhibits these same features. The EMT model also exhibits the same tendencies (Figure 11c), but the range of soil moisture values, particularly in dry areas of the catchment, is less than what is produced by the EOF method. Both of the downscaled patterns lack the local variations in the observed soil moisture pattern. When the $K_{s, v}$ data are added to the EOF method (Figure 11c), the downscaled pattern appears almost unchanged. The EOF method does use the $K_{s, v}$ data, but they have very little effect on the results. The soil moisture pattern produced by the EMT+VS model reflects the variations in $K_{s, v}$ that are shown in Figure 5b. In particular, locations with larger $K_{s, v}$ values are slightly drier in the downscaled pattern, a pattern that can be seen in the observed soil moisture pattern. This occurs because the EMT+VS model uses the $K_{s, v}$ data to produce the DDI and LFI patterns and both deep drainage and lateral flow are of greater importance than radiative $\mathrm{ET}$.

Table 8 quantifies the average performance of these downscaling methods when applied to all dates in the Tarrawarra dataset. When the $K_{s, v}$ data are included in the EOF method, the performance remains almost unchanged from the case when only topographic data are used. When the $K_{s, v}$ data are included in the EMT+VS model, the performance decreases. In both cases, the results suggest that the interpolated $K_{s, v}$ data are not reliable. The EOF method uses only attributes that are correlated with the EOFs, so the similarity of the results suggests that the interpolated $K_{s, v}$ data do not have a strong linear relationship to the EOFs. The EMT+VS model must use the supplied $K_{s, v}$ map. If those data are not reliable, then the performance will be 
poorer than calibrating a single $K_{s, v}$ value (i.e. applying the EMT model). It is also possible that both the EOF and EMT+VS models have errors in their model structures that make them incapable of using the $K_{s, v}$ data. However, given the substantial differences between the structures of the two models, this cause is unlikely.

Next, the EMT+VS model is applied using both the interpolated $K_{s, v}$ map and the maps for the soil parameters $\delta_{0}$ and $\kappa_{\text {min }}$. For both the EOF method and EMT+VS model, including this additional data does not substantially affect the downscaled soil moisture patterns (bottom row of Figure 11). The EOF method chooses not use the $\delta_{0}$ and $\kappa_{\min }$ data. In particular, Figure $11 \mathrm{e}$ and $11 \mathrm{~h}$ are identical, and Figures $11 \mathrm{f}$ and $11 \mathrm{i}$ are very similar. The performance metrics in Table 8 suggest that the average performance from all dates is also nearly unchanged for the EMT+VS model. Thus, the EMT+VS model performs the same when the calibrated values of $\delta_{0}$ and $\kappa_{\text {min }}$ are replaced with the patterns determined from data.

\subsection{Nerrigundah}

At Nerrigundah, the EMT+VS model's use of fine-resolution $K_{s, v}$ and $\phi$ data is evaluated. The model is first applied when only the fine-resolution $K_{s, v}$ data are included and uses the same topographic data as the EMT model. Figure 12 shows the downscaled patterns for an example date. Calibrated parameters and spatially-constant variables for Nerrigundah tests can be seen in Table 9. The observed soil moisture pattern exhibits wetter conditions on the SFS than the NFS in the eastern half of the catchment (Figure 12a). The western half of the catchment is generally drier than the eastern half of the catchment and exhibits little dependence on hillslope orientation. When only topographic data are used in the EOF method (Figure 12b) and the EMT model (Figure 12c), the downscaled patterns also exhibit the wetter conditions for 
the SFS than the NFS, but the difference between the eastern and western halves is of the catchment is not as pronounced for the EOF method and is not reproduced for the EMT model. When the $K_{s, v}$ data are added to the EOF method (Figure 12e) and EMT+VS model (Figure 12f), the downscaled patterns more closely resemble the features of the interpolated $K_{s, v}$ pattern. For the EOF method, two drier spots are modeled on the eastern portion of the catchment, which correspond to higher areas of $K_{s, v}$, while a wetter region on the west half of the catchment is modeled, which correspond to region of lower $K_{s, v}$ (Figure 6b). The EMT+VS model models the drier region on the south portion of the eastern half of the catchment, but less of the $K_{s, v}$ pattern can be seen as compared to the EOF method. The EMT+VS pattern is controlled primarily by both REI and DDI, with the importance of radiative ET being about 1.5 times larger than that of deep drainage. Because DDI is dependent on $K_{s, v}$, the downscaling patterns reflect some of the $K_{s, v}$ pattern. But because the importance of radiative ET, which is independent of $K_{s, v}$, is greater than that of deep drainage, not all of the $K_{s, v}$ pattern can be seen in soil moisture patterns. The performance metrics in Table 10 show an increase in average performance from when topography alone is used to when both topography and $K_{s, v}$ are used. This indicates that addition of fine-resolution $K_{s, v}$ data into the EMT+VS model can be beneficial.

Next, the EOF method and EMT+VS model are applied when both the fine-resolution $K_{s, v}$ and $\phi$ datasets are provided. For the example date, the EOF method produces an identical pattern (Figure 12h) to the case when only fine-resolution topographic and $K_{s, v}$ data were included (Figure 12e). The similarity suggests that the $\phi$ data are not strongly associated with 
the EOFs. However, when the $\phi$ data are added to the EMT+VS model (Figure 12i), the downscaled pattern differs from the previous case (Figure 12f). The EMT+VS model must use the $\phi$ data in all four of its indices. As a result, several drier patches now occur, the most obvious one being located on the center edge of the SFS, as seen in Figure 12i. Although these patches do not precisely align with dry patches in the observed pattern, the observed pattern does have dry patches at similar locations. This result suggests that the EMT+VS model might be capturing variations in soil moisture that are due to $\phi$ variations, but that the interpolated $\phi$ map does not correctly identify the configuration of those variations.

Table 10 shows that the average performance of the EOF method is unchanged from the previous case because the $\phi$ data are not used. This result suggests that the interpolated $\phi$ data are likely unreliable or that the empirical structure of the EOF model is not capable of using these data. Table 10 also shows that the average performance of the EMT+VS model decreases when the $\phi$ map is included. Even though the soil moisture variations that are produced by the $\phi$ variations appear realistic in Figure 12, including these variations produces worse overall performance. Because neither model benefits from use of the $\phi$ map, it is likely that this map is unreliable. 


\section{CHAPTER 6: CONCLUSIONS}

This thesis aimed to generalize the EMT model to allow it to accept fine-resolution data for vegetation and soil properties based on the hypothesis that the consideration of spatial variations in vegetation and soil characteristics would improve the model's ability to downscale soil moisture patterns. Based on this study, the following conclusions can be made:

1. The new EMT+VS model is successful at capturing some of the effects of vegetation cover on the soil moisture patterns at the Cache la Poudre catchment. When vegetation cover is included in the EMT+VS model, its performance is better than that of the EMT model, which uses only topographic variations to downscale. In addition, the EMT+VS model outperforms the EOF method when both methods are provided with similar information, which suggests that the representation of vegetation in the EMT+VS model is superior to linear regressions that are used in the EOF method.

2. Fine-resolution variations in vegetation cover play a substantial role in determining the soil moisture patterns at Cache la Poudre. When the vegetation cover data are added to the EMT+VS model, the average NSCE increases from 0.080 to 0.134 . In this catchment, the vegetation cover varies dramatically between forests on the NFS and shrublands on the SFS. Vegetation is expected to play a smaller role in catchments where it is more homogeneous.

3. The main mechanism by which vegetation influences soil moisture at the Cache la Poudre catchment is the associated reduction in soil evaporation. Vegetation can reduce evaporation by shading the surface, reducing the wind speed near the surface, and reducing the humidity gradient. When interception is neglected in the EMT+VS model, 
the model performance is nearly unchanged. Because interception and root-water uptake do not play a large role in the Cache la Poudre dataset, further testing is needed to evaluate their representations in the EMT+VS model.

4. Fine-resolution variations in saturated hydraulic conductivity and porosity play a much smaller role in determining the Cache la Poudre soil moisture patterns. The addition of fine-resolution saturated hydraulic conductivity and porosity data does not significantly improve the performance of EMT+VS model or the EOF method in this catchment. Hydraulic conductivity affects the deep drainage and lateral flow processes, which are determined to not be important when the EMT or EMT+VS models are applied to the Cache la Poudre dataset. The small improvement in performance is mainly due to the inclusion of the porosity data.

5. The EMT+VS model performance is sensitive to the quality of the fine-resolution soil data. The EOF method can disregard data that are not helpful for predicting the soil moisture patterns, but the EMT+VS model must use supplied soil data. For the Tarawarra and Nerrigundah catchments, the sparse data for soil characteristics were interpolated using IWD to produce fine-resolution maps, but the use of those maps in the EMT+VS model generally produced similar or worse performance than using calibrated constant values for those characteristics.

Overall, the results suggest that the use of fine-resolution vegetation data is a promising direction for improving soil moisture downscaling methods, particularly for catchments where vegetation cover exhibits substantial variations. In addition, they suggest that the EMT+VS model can efficiently use such vegetation data. However, further research is needed to determine whether remotely-sensed measures of vegetation cover such as LAI are beneficial in the 
EMT+VS model. Also, new datasets are needed to determine whether the representations of interception and transpiration are reliable. In contrast, the results suggest that the use of fineresolution soil information for downscaling is more problematic. Throughout this study, the use of fine-resolution maps for soil properties usually degraded the performance of the EMT+VS model and did not change the performance for the EOF method. In the case of Cache la Poudre, the available soil properties were not important to the soil moisture patterns. For the other catchments, the available data were too sparse to be useful in the downscaling methods. While spatial variations in soil properties are known to be important in determining soil moisture variations in some cases, high quality data for appropriate soil properties are needed to improve the performance of the downscaling methods. 


\section{TABLES}

Table 1. Summary of characteristics and data for the three test catchments.

\begin{tabular}{l|ccc}
\hline Catchment & Cache la Poudre & Tarrawarra & Nerrigundah \\
\hline Area (ha) & 8.0 & 10.5 & 6.0 \\
$\begin{array}{l}\text { Annual } \\
\text { Precipitation (mm) }\end{array}$ & 415 & 820 & 1000 \\
\hline $\begin{array}{l}\text { Soil Moisture } \\
\text { Measurement Dates }\end{array}$ & 9 & 13 & 12 \\
$\begin{array}{l}\text { Soil Moisture } \\
\text { Measurement Depth } \\
\text { (cm) }\end{array}$ & 5 & 30 & 15 \\
$\begin{array}{l}\text { Soil Moisture } \\
\text { Sampling Grid (m) }\end{array}$ & 15 & $10 \times 20$ & 20 \\
\hline $\begin{array}{l}\text { Topographic } \\
\text { Sampling Grid (m) }\end{array}$ & 15 & 5 & 20 \\
\hline $\begin{array}{l}\text { Vegetation Data } \\
\text { Litter depth, canopy } \\
\text { cover }\end{array}$ & N/A & N/A \\
Soil Data & Soil texture & $\begin{array}{c}\text { Saturated hydraulic } \\
\text { conductivity, soil } \\
\text { depth }\end{array}$ & $\begin{array}{c}\text { Saturated hydraulic } \\
\text { conductivity, } \\
\text { porosity, soil depth }\end{array}$ \\
\hline
\end{tabular}


Table 2. Upper and lower calibration ranges for model parameters and spatially-constant variables at all three test catchments.

\begin{tabular}{c|cc|cc|cc}
\hline \multirow{2}{*}{ Parameter } & \multicolumn{2}{|c|}{ Poudre } & \multicolumn{2}{c|}{ Tarrawarra } & \multicolumn{2}{c}{ Nerrigundah } \\
& Lower & Upper & Lower & Upper & Lower & Upper \\
\hline$E_{p}(\mathrm{~mm} /$ day $)$ & 2.4 & 2.4 & 2.3 & 2.3 & 2.8 & 2.8 \\
$\alpha$ & 0.26 & 0.26 & 0.26 & 0.26 & 0.26 & 0.26 \\
\hline$\beta_{r}$ & 0.2 & 5 & 0.2 & 5 & 0.2 & 5 \\
$\beta_{a}$ & 0.2 & 5 & 0.2 & 5 & 0.2 & 5 \\
$\eta$ & 0 & 1 & 0 & 1 & 0 & 1 \\
$\lambda$ & 0 & 1 & 0 & 1 & 0 & 1 \\
$\mu$ & 1 & 3 & 1 & 3 & 1 & 3 \\
$\zeta(\mathrm{m})$ & 0.001 & $\mathrm{~N} / \mathrm{A}$ & $\mathrm{N} / \mathrm{A}$ & $\mathrm{N} / \mathrm{A}$ & $\mathrm{N} / \mathrm{A}$ & $\mathrm{N} / \mathrm{A}$ \\
\hline$\phi\left(\mathrm{m}^{3} / \mathrm{m}^{3}\right)$ & 0.38 & 0.41 & 0.25 & 0.70 & 0.41 & 0.56 \\
$K_{s, v}(\mathrm{~mm} / \mathrm{day})$ & 936 & 1845 & 17 & 3355 & 36 & 2592 \\
$\imath$ & 1 & 100 & 1 & 100 & 1 & 100 \\
$\gamma_{h}$ & 1.0 & 13.0 & 1.0 & 25.0 & 1.0 & 17.3 \\
$\gamma_{v}$ & 9.2 & 13.0 & 4.0 & 25.0 & 10.9 & 17.3 \\
$\delta_{0}(\mathrm{~m})$ & 0.05 & 0.05 & 0.23 & 0.23 & 0.25 & 0.25 \\
$\kappa_{\text {min }}(1 / \mathrm{m})$ & $-1 \mathrm{E}+06$ & -0.0560 & -0.0267 & -0.0267 & $-1 \mathrm{E}+06$ & -0.0056 \\
$\varepsilon$ & 1 & 3 & 1 & 3 & 1 & 3 \\
\hline
\end{tabular}


Table 3. Model parameters and spatially-constant variables for Cache la Poudre tests on a $15 \mathrm{~m}$ grid. All parameters other than climate parameters are calibrated.

\begin{tabular}{c|c|c}
\hline Parameter & EMT & $\begin{array}{c}\text { EMT+VS: } \\
\text { Topography and } \\
\text { Vegetation }\end{array}$ \\
\hline$E_{p}(\mathrm{~mm} /$ day $)$ & 2.4 & 2.4 \\
$\alpha$ & 0.26 & 0.26 \\
\hline$\beta_{r}$ & 5.0 & 4.5 \\
$\beta_{a}$ & 4.8 & 3.0 \\
$\eta$ & N/A & 0.06 \\
$\lambda$ & N/A & 0.83 \\
$\mu$ & N/A & 1.85 \\
$\zeta(\mathrm{m})$ & N/A & 0.03 \\
\hline$\phi\left(\mathrm{m}^{3} / \mathrm{m}^{3}\right)$ & 0.38 & 0.41 \\
$K_{s, v}(\mathrm{~mm} / \mathrm{day})$ & 941 & 941 \\
$\imath$ & 1 & 5 \\
$\gamma_{h}$ & 4.3 & 9.2 \\
$\gamma_{v}$ & 12.1 & 13.0 \\
$\delta_{0}(\mathrm{~m})$ & 0.05 & 0.05 \\
$\kappa_{\text {min }}(1 / \mathrm{m})$ & -0.056 & -15.136 \\
$\varepsilon$ & 2.38 & 3.00 \\
\hline
\end{tabular}


Table 4. Measures of model performance when the downscaling models are applied to Cache la Poudre. The scenarios represent the fine-resolution data included in the tested model. The top half of the table represents topography and vegetation data on a $15 \mathrm{~m}$ grid while the bottom half of the table represents topography, vegetation, and soils data on a $30 \mathrm{~m}$ grid. The NSCE, RMSE, and MRE are calculated separately for each of the 9 days in the dataset and then the averages, maximums, and minimums are determined from the different dates.

\begin{tabular}{c|c|c|ccc|cc}
\hline \multirow{2}{*}{ Grid } & Scenario & \multirow{2}{*}{ Model } & \multicolumn{3}{c|}{ NSCE } & RMSE & MRE \\
& & & Avg. & Max. & Min. & Avg. & Avg. \\
\hline \multirow{4}{*}{$15 \mathrm{~m}$} & Topography & EMT & 0.080 & 0.183 & -0.027 & 0.031 & 0.453 \\
& Topography and & EOF & 0.116 & 0.288 & -0.050 & 0.030 & 0.438 \\
\cline { 2 - 8 } & Vegetation & EOF & 0.129 & 0.320 & -0.070 & 0.030 & 0.434 \\
\hline \multirow{3}{*}{$30 \mathrm{~m}$} & EMT & 0.099 & 0.227 & 0.015 & 0.030 & 0.485 \\
& Topography & EOF & 0.172 & 0.399 & -0.030 & 0.028 & 0.448 \\
\cline { 2 - 8 } & Topography and & EMT+VS & 0.187 & 0.498 & -0.089 & 0.029 & 0.463 \\
& Vegetation & EOF & 0.190 & 0.405 & 0.008 & 0.028 & 0.453 \\
\cline { 2 - 8 } & Topography, & EMT+VS & 0.189 & 0.488 & -0.081 & 0.028 & 0.458 \\
& Veg., and Soil $\left(K_{s, v}\right)$ & EOF & 0.226 & 0.391 & 0.050 & 0.027 & 0.437 \\
\cline { 2 - 8 } & Topography, & EMT+VS & 0.196 & 0.495 & -0.080 & 0.028 & 0.457 \\
& Veg., and Soil $\left(K_{s, v}\right.$ and $\left.\phi\right)$ & EOF & 0.226 & 0.391 & 0.050 & 0.027 & 0.437 \\
\hline
\end{tabular}


Table 5. Measures of standard deviations when the downscaling models are applied to Cache la Poudre. The scenarios represent the observed conditions or fine-resolution data included in the tested model. The top half of the table represents topography and vegetation data on a $15 \mathrm{~m}$ grid while the bottom half of the table represents topography, vegetation, and soils data on a $30 \mathrm{~m}$ grid. The standard deviations are calculated separately for each of the 9 days in the dataset and then the averages, maximums, and minimums are determined from the different dates.

\begin{tabular}{c|c|c|ccc}
\hline \multirow{3}{*}{ Grid } & \multirow{2}{*}{ Scenario } & Model & \multicolumn{3}{c}{ St. Dev. } \\
& Observed & & Avg. & Max. & Min. \\
\hline \multirow{4}{*}{$15 \mathrm{~m}$} & Topography & EMT & 0.008 & 0.013 & 0.005 \\
\cline { 2 - 6 } & Topography and & EOF & 0.010 & 0.016 & 0.006 \\
\cline { 2 - 6 } & Vegetation & EOF & 0.011 & 0.016 & 0.006 \\
\hline \multirow{5}{*}{$30 \mathrm{~m}$} & Observed & & 0.031 & 0.039 & 0.021 \\
\cline { 2 - 6 } & Topography & EMT & 0.009 & 0.015 & 0.005 \\
\cline { 2 - 6 } & Topography and & EMT+VS & 0.012 & 0.017 & 0.008 \\
\cline { 2 - 6 } & Vegetation & EOF & 0.014 & 0.019 & 0.005 \\
& Topography, & EMT+VS & 0.012 & 0.020 & 0.0009 \\
\cline { 2 - 6 } & Veg., and Soil $\left(K_{s, v}\right)$ & EOF & 0.015 & 0.020 & 0.009 \\
\cline { 2 - 6 } & Topography, & EMT+VS & 0.012 & 0.021 & 0.006 \\
& Veg., and Soil $\left(K_{s, v}\right.$ and $\left.\phi\right)$ & EOF & 0.015 & 0.020 & 0.009 \\
\hline
\end{tabular}


Table 6. Model parameters and spatially-constant variables for Cache la Poudre tests on a $30 \mathrm{~m}$ grid. All parameters other than climate parameters are calibrated.

\begin{tabular}{c|c|c|c|c}
\hline Parameter & EMT & $\begin{array}{c}\text { EMT+VS: } \\
\text { Topography and } \\
\text { Vegetation }\end{array}$ & $\begin{array}{c}\text { EMT+VS: } \\
\text { Topography, } \\
\text { Veg., and Soil } \\
\left(K_{s, v}\right)\end{array}$ & $\begin{array}{c}\text { EMT+VS: } \\
\text { Topography, } \\
\text { Veg., and Soil } \\
\left(K_{s, v} \text { and } \phi\right)\end{array}$ \\
\hline$E_{p}(\mathrm{~mm} /$ day $)$ & 2.4 & 2.4 & 2.4 & 2.4 \\
$\alpha$ & 0.26 & 0.26 & 0.26 & 0.26 \\
\hline$\beta_{r}$ & 5.0 & 5.0 & 5.0 & 5.0 \\
$\beta_{a}$ & 4.7 & 3.8 & 3.8 & 3.7 \\
$\eta$ & N/A & 0.13 & 0.12 & 0.12 \\
$\lambda$ & N/A & 0.07 & 0.17 & 0.17 \\
$\mu$ & N/A & 1.00 & 1.00 & 1.00 \\
$\zeta(\mathrm{m})$ & N/A & 0.01 & 0.01 & 0.01 \\
\hline$\phi\left(\mathrm{m}^{3} / \mathrm{m}^{3}\right)$ & 0.39 & 0.41 & 0.41 & N/A \\
$K_{s, v}(\mathrm{~mm} / \mathrm{day})$ & 936 & 943 & $\mathrm{~N} / \mathrm{A}$ & N/A \\
$\imath$ & 1 & 1 & 1 & 1 \\
$\gamma_{h}$ & 4.6 & 4.1 & 4.3 & 4.4 \\
$\gamma_{v}$ & 11.9 & 12.2 & 12.6 & 12.9 \\
$\delta_{0}(\mathrm{~m})$ & 0.05 & 0.05 & 0.05 & 0.05 \\
$\kappa_{\text {min }}(1 / \mathrm{m})$ & -0.056 & -1391.569 & -0.056 & -0.056 \\
$\varepsilon$ & 1.22 & 2.98 & 3.00 & 2.72 \\
\hline
\end{tabular}


Table 7. Model parameters and spatially-constant variables for Tarrawarra tests on a 10 by $20 \mathrm{~m}$ grid. All parameters other than climate parameters are calibrated.

\begin{tabular}{c|c|c|c}
\hline Parameter & EMT & $\begin{array}{c}\text { EMT+VS: } \\
\text { Topography and } \\
\text { Soil }\left(K_{s, v}\right)\end{array}$ & $\begin{array}{c}\text { EMT+VS: } \\
\text { Topography, } \\
\text { Veg., and Soil } \\
\left(K_{s, v} \text { and } \delta_{0} /\right. \\
\left.\kappa_{\text {min }}\right)\end{array}$ \\
\hline$E_{p}(\mathrm{~mm} /$ day $)$ & 2.3 & 2.3 & 2.3 \\
$\alpha$ & 0.26 & 0.26 & 0.26 \\
\hline$\beta_{r}$ & 3.6 & 4.3 & 4.3 \\
$\beta_{a}$ & 5.0 & 5.0 & 5.0 \\
$\eta$ & N/A & 0.00 & 0.00 \\
$\lambda$ & N/A & 0.38 & 0.67 \\
$\mu$ & N/A & 1.43 & 1.83 \\
$\zeta(\mathrm{m})$ & N/A & N/A & N/A \\
\hline$\phi\left(\mathrm{m}^{3} / \mathrm{m}^{3}\right)$ & 0.70 & 0.70 & 0.70 \\
$K_{s, v}(\mathrm{~mm} / \mathrm{day})$ & 459 & N/A & N/A \\
$\imath$ & 64 & 100 & 100 \\
$\gamma_{h}$ & 6.9 & 16.5 & 16.6 \\
$\gamma_{v}$ & 14.1 & 25.0 & 25.0 \\
$\delta_{0}(\mathrm{~m})$ & 0.23 & 0.23 & N/A \\
$\kappa_{\min }(1 / \mathrm{m})$ & -0.027 & -0.027 & N/A \\
$\varepsilon$ & 1 & 1 & 1 \\
\hline$\varepsilon$ & & &
\end{tabular}


Table 8. Measures of model performance when the downscaling models are applied to Tarrawarra. The scenarios represent the fine-resolution data included in the tested model. The NSCE, RMSE, and MRE are calculated separately for each of the 13 days in the dataset and then the averages, maximums, and minimums are determined from the different dates.

\begin{tabular}{c|c|ccc|c|c}
\hline \multirow{2}{*}{ Scenario } & \multirow{2}{*}{ Model } & NSCE & RMSE & MRE \\
& & Avg. & Max. & Min. & Avg. & Avg. \\
\hline Topography & EMT & 0.290 & 0.562 & 0.045 & 0.028 & 0.064 \\
& EOF & 0.350 & 0.655 & 0.068 & 0.027 & 0.061 \\
\hline Topography and & EMT+VS & 0.256 & 0.550 & -0.026 & 0.029 & 0.066 \\
Soil $\left(K_{s, v}\right)$ & EOF & 0.356 & 0.662 & 0.077 & 0.027 & 0.061 \\
\hline Topography and & EMT+VS & 0.258 & 0.555 & -0.027 & 0.029 & 0.066 \\
Soil $\left(K_{s, v}\right.$ and $\left.\delta_{0} / \kappa_{\text {min }}\right)$ & EOF & 0.356 & 0.662 & 0.077 & 0.027 & 0.061 \\
\hline
\end{tabular}


Table 9. Model parameters and spatially-constant variables for Nerrigudah tests on a $20 \mathrm{~m}$ grid. All parameters other than climate parameters are calibrated.

\begin{tabular}{c|c|c|c}
\hline Parameter & EMT & $\begin{array}{c}\text { EMT+VS: } \\
\text { Topography and } \\
\text { Soil }\left(K_{s, v}\right)\end{array}$ & $\begin{array}{c}\text { EMT+VS: } \\
\text { Topography, } \\
\text { Veg., and Soil } \\
\left(K_{s, v} \text { and } \phi\right)\end{array}$ \\
\hline$E_{p}(\mathrm{~mm} /$ day $)$ & 2.8 & 2.8 & 2.8 \\
$\alpha$ & 0.26 & 0.26 & 0.26 \\
\hline$\beta_{r}$ & 1.6 & 1.1 & 1.1 \\
$\beta_{a}$ & 5.0 & 5.0 & 5.0 \\
$\eta$ & N/A & 0.00 & 1.00 \\
$\lambda$ & N/A & 0.43 & 0.36 \\
$\mu$ & N/A & 2.79 & 1.65 \\
$\zeta(\mathrm{m})$ & N/A & N/A & N/A \\
\hline$\phi\left(\mathrm{m}^{3} / \mathrm{m}^{3}\right)$ & 0.47 & 0.555 & N/A \\
$K_{s, v}(\mathrm{~mm} /$ day $)$ & 69 & N/A & 36 \\
$\iota$ & 100 & 14 & 4.8 \\
$\gamma_{h}$ & 4.7 & 5.0 & 10.9 \\
$\gamma_{v}$ & 17.3 & 10.9 & 0.25 \\
$\delta_{0}(\mathrm{~m})$ & 0.25 & 0.25 & -0.016 \\
$\kappa_{\min }(1 / \mathrm{m})$ & -45561.777 & -0.043 & 1 \\
$\varepsilon$ & 1 & 1 & \\
\hline
\end{tabular}


Table 10. Measures of model performance when the downscaling models are applied to Nerrigundah. The attributes represent the fine-resolution data included in the tested model. The NSCE, RMSE, and MRE are calculated separately for each of the 12 days in the dataset and then the averages, maximums, and minimums are determined from the different dates.

\begin{tabular}{c|c|ccc|c|c}
\hline Scenarios & \multirow{2}{*}{ Model } & Avg. & Max. & Min. & Avg. & $\begin{array}{c}\text { Avg. } \\
\text { AvE }\end{array}$ \\
\hline \multirow{2}{*}{ Topography } & EMT & 0.182 & 0.222 & 0.143 & 0.048 & 0.165 \\
& EOF & 0.274 & 0.326 & 0.087 & 0.045 & 0.155 \\
\hline Topography and & EMT+VS & 0.218 & 0.281 & 0.088 & 0.047 & 0.161 \\
Soil $\left(K_{s, v}\right)$ & EOF & 0.288 & 0.345 & 0.171 & 0.045 & 0.151 \\
\hline Topography and & EMT+VS & 0.115 & 0.282 & -0.022 & 0.050 & 0.170 \\
Soil $\left(K_{s, v}\right.$ and $\left.\phi\right)$ & EOF & 0.288 & 0.345 & 0.171 & 0.045 & 0.151 \\
\hline
\end{tabular}




\section{FIGURES}
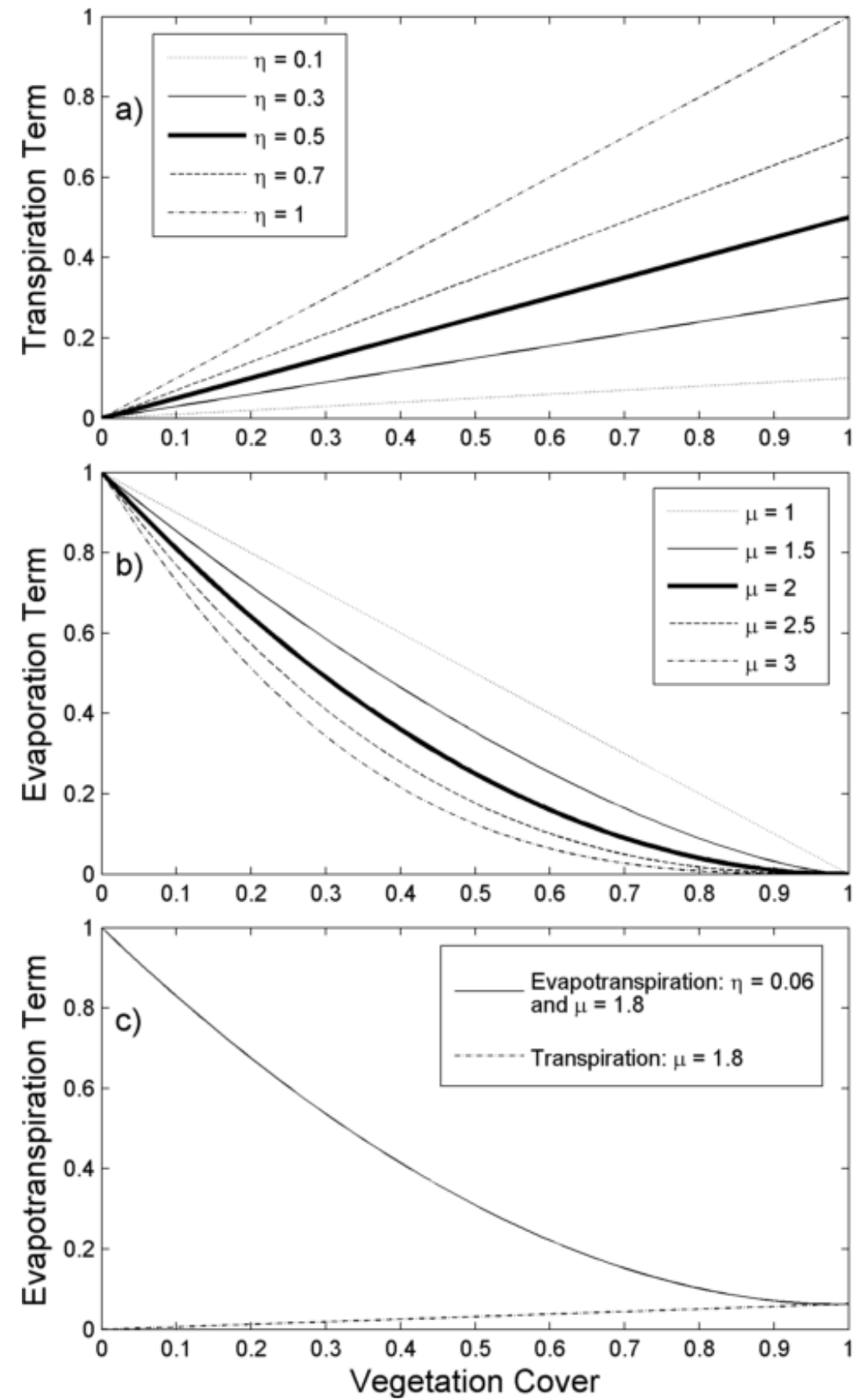

Figure 1. (a) Transpiration term, (b) evaporation term, and (c) sum of transpiration and evaporation terms in the EMT+VS model's ET equation plotted as a function of vegetation cover $V$. Part (c) also shows the portion of the sum that is contributed by the transpiration term. 


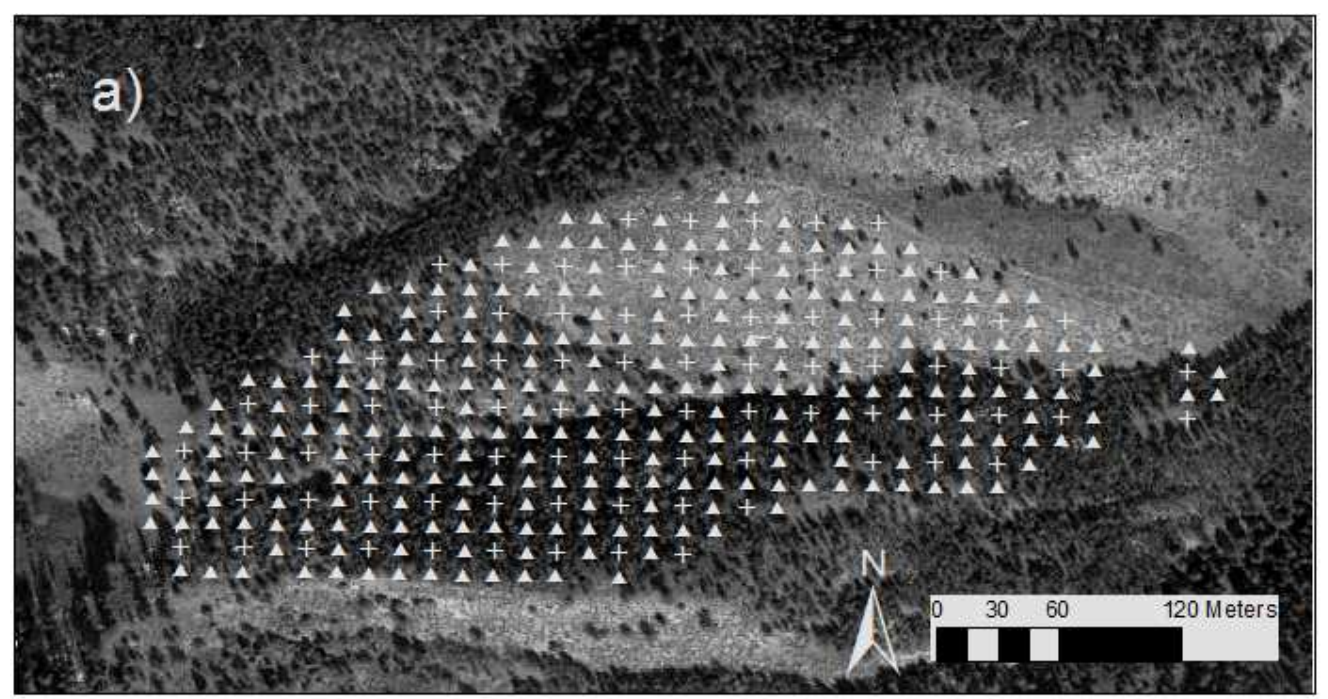

b)

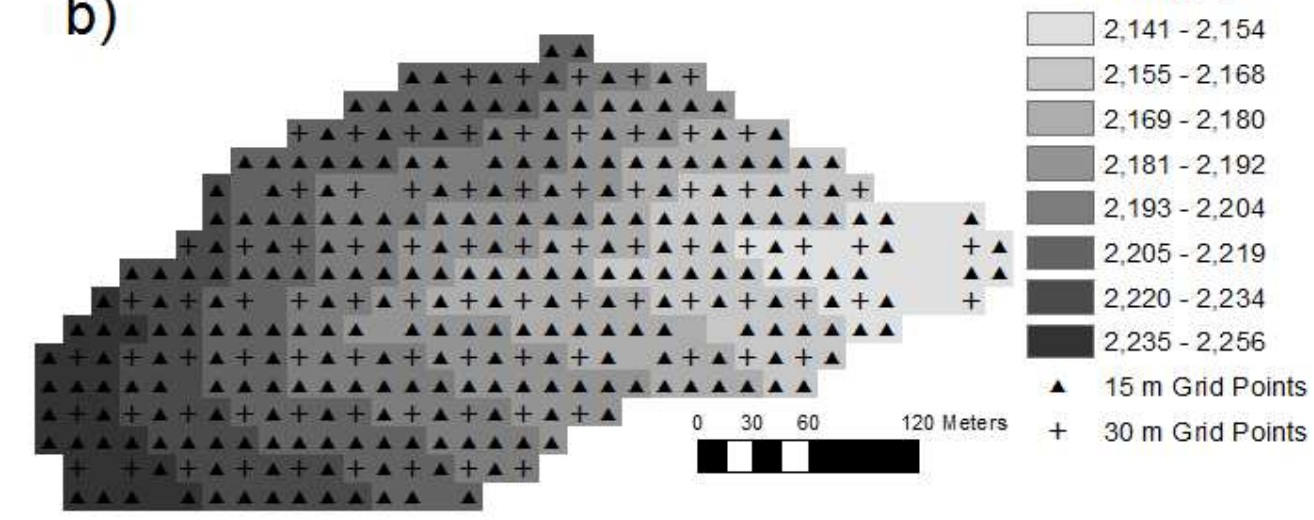

Figure 2. The primary test catchment, Cache la Poudre, (a) $15 \mathrm{~m}$ and $30 \mathrm{~m}$ sampling grids overlaid on aerial photo, and (b) sampling grids overlaid on catchment topography. 
a) Litter Depth (m)

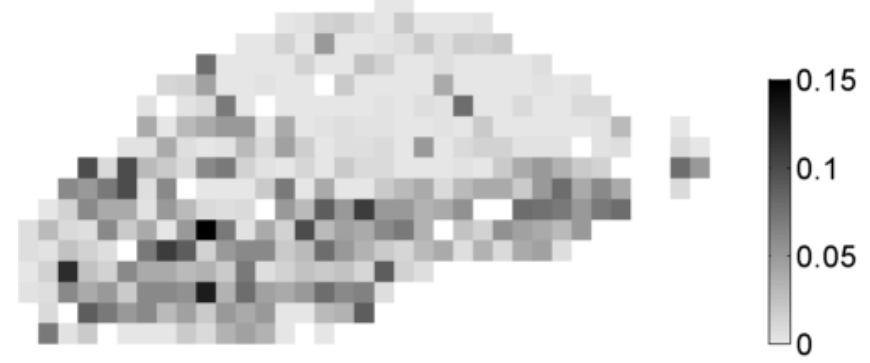

b) Canopy Cover

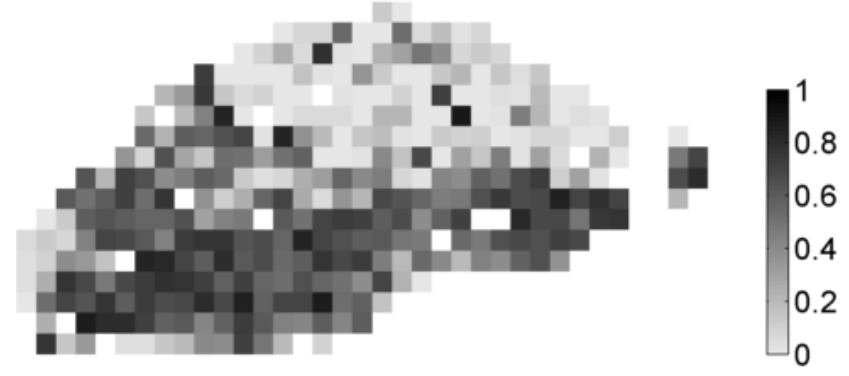

c) Vegetation Cover

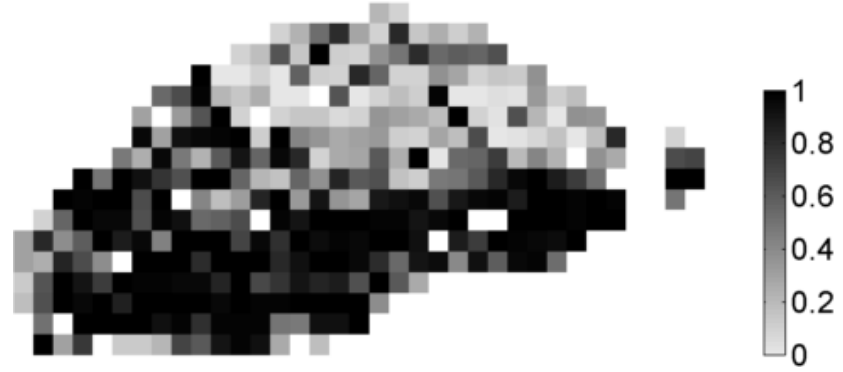

Figure 3. Vegetation data collected at the Cache la Poudre Catchment with (a) representing litter depth measurements (m); (b) representing fractional canopy cover; and (c) representing the calculated fractional vegetation cover, $V=L_{c}+C_{c}-L_{c} C_{c}$, where the calibrated reference depth $\zeta=0.03 \mathrm{~m}$ for the case when EMT+VS model is run with only topographic and vegetation data. 

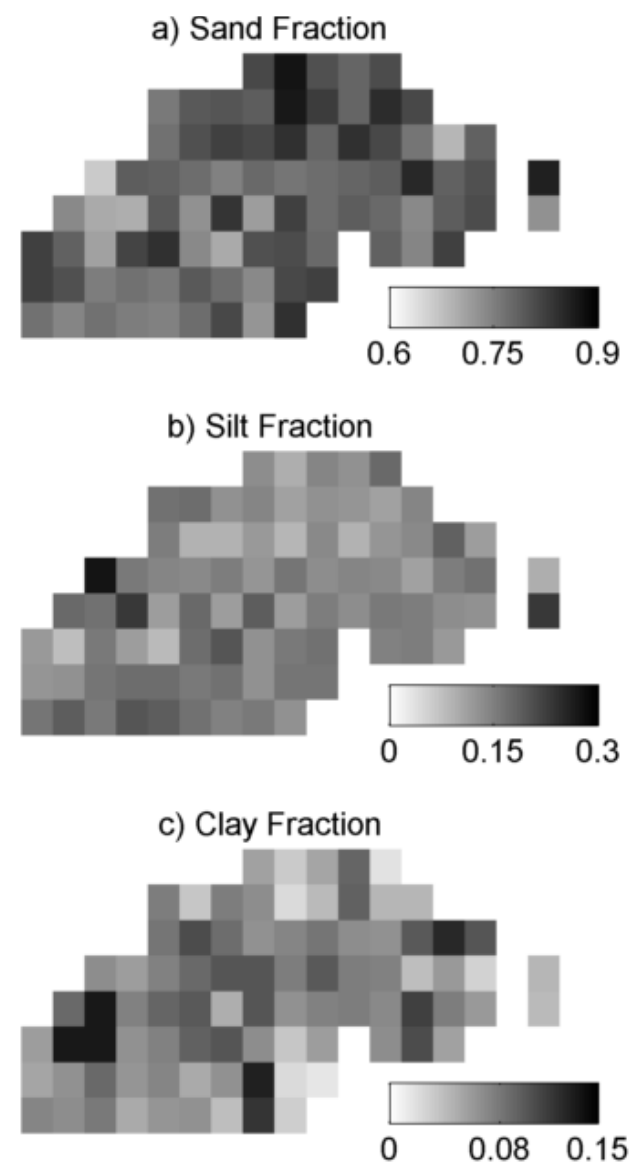

d) Saturated Hydraulic Conductivity ( $\mathrm{mm} /$ day)
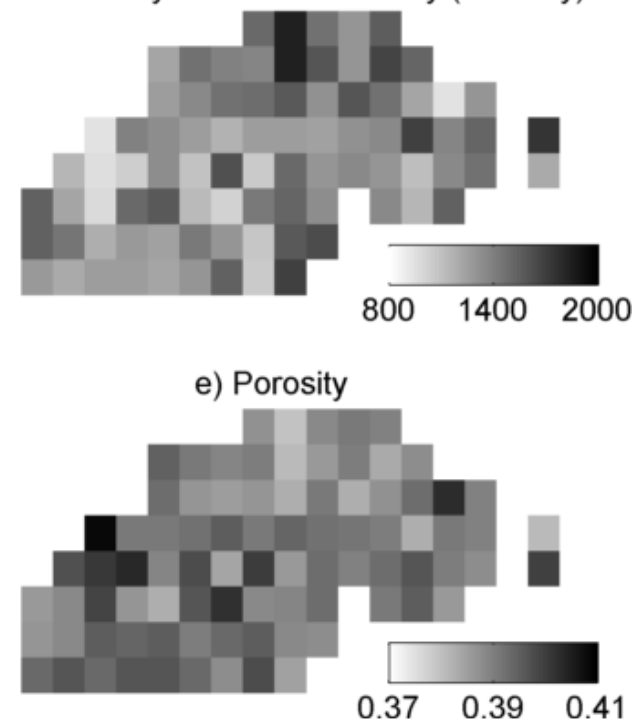

Figure 4. (a) Sand, (b) silt, and (c) clay fractions determined from soil texture measurements at Cache la Poudre catchment. (d) Saturated hydraulic conductivity and (e) porosity were calculated using pedotransfer functions from Cobsy (1984) using (a) and (c). 

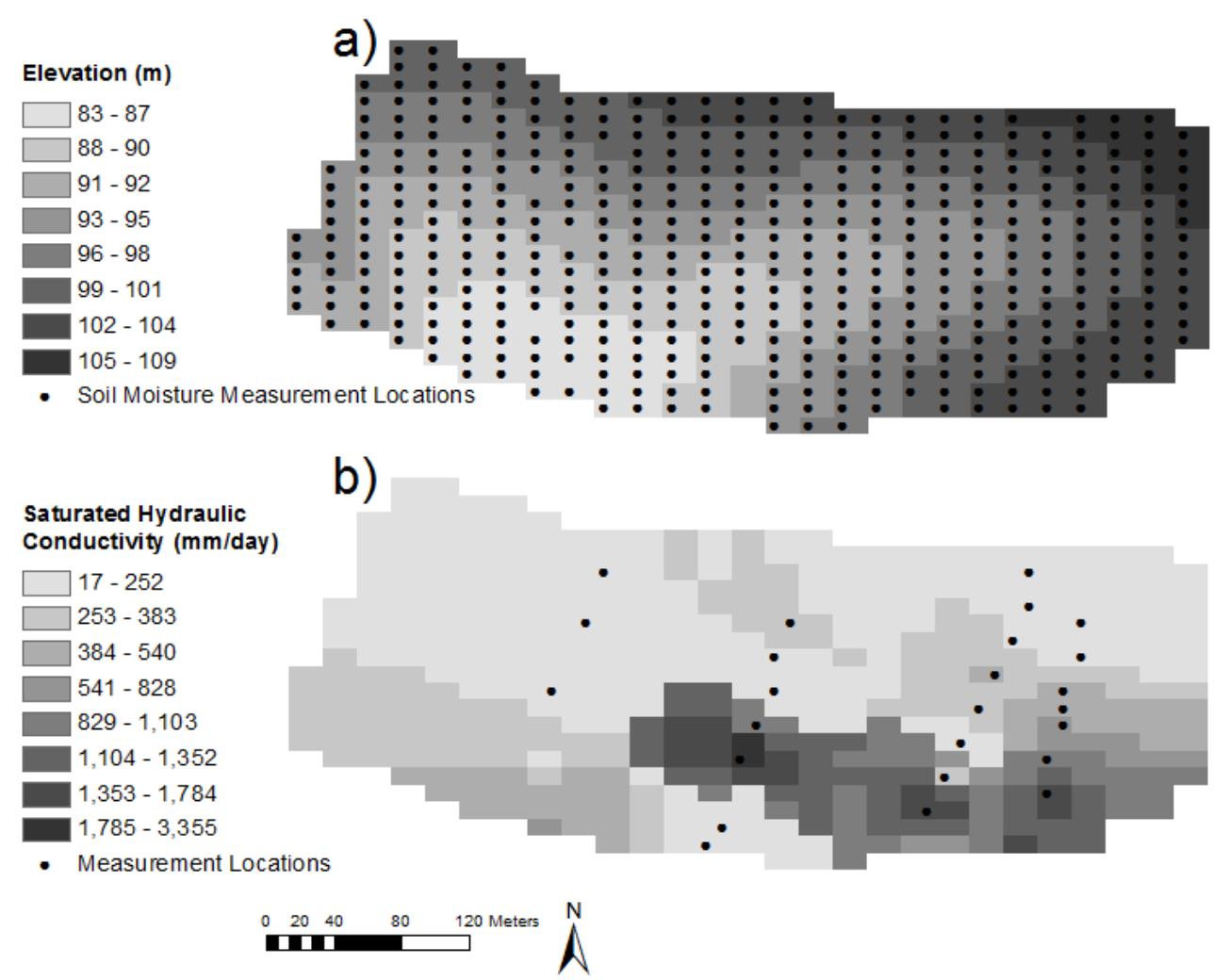

Figure 5. Supplemental test catchment, Tarrawarra, (a) soil moisture sampling grid overlaid on the catchment topography and (b) saturated hydraulic conductivity measurement locations overlaid on the interpolated conductivity map. 

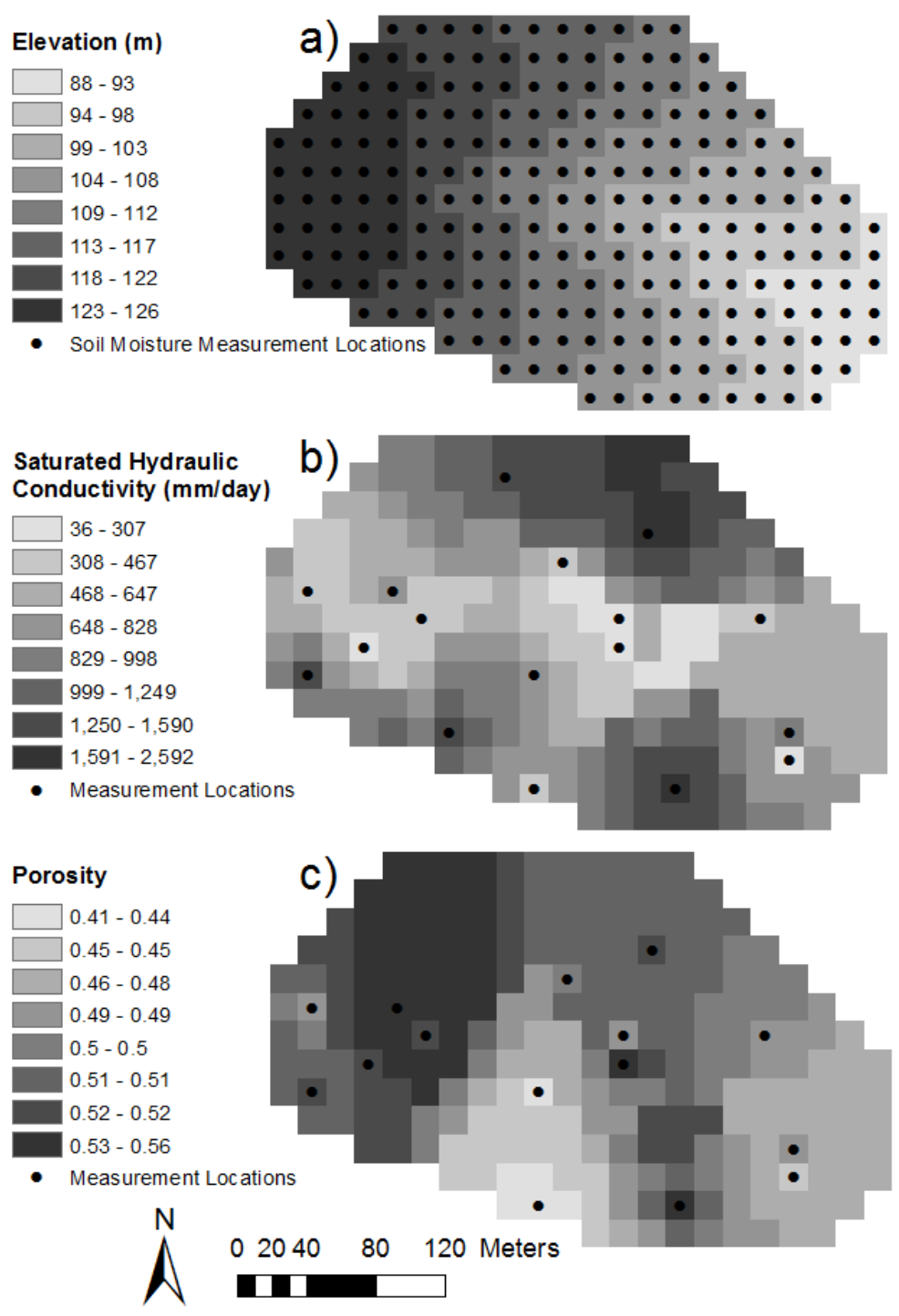

Figure 6. Supplemental test catchment, Nerrigundah, (a) soil moisture sampling grid overlaid on the catchment topography, (b) saturated hydraulic conductivity measurement locations overlaid on the interpolated conductivity map, and (c) porosity measurement locations overlaid on the interpolated porosity map. 


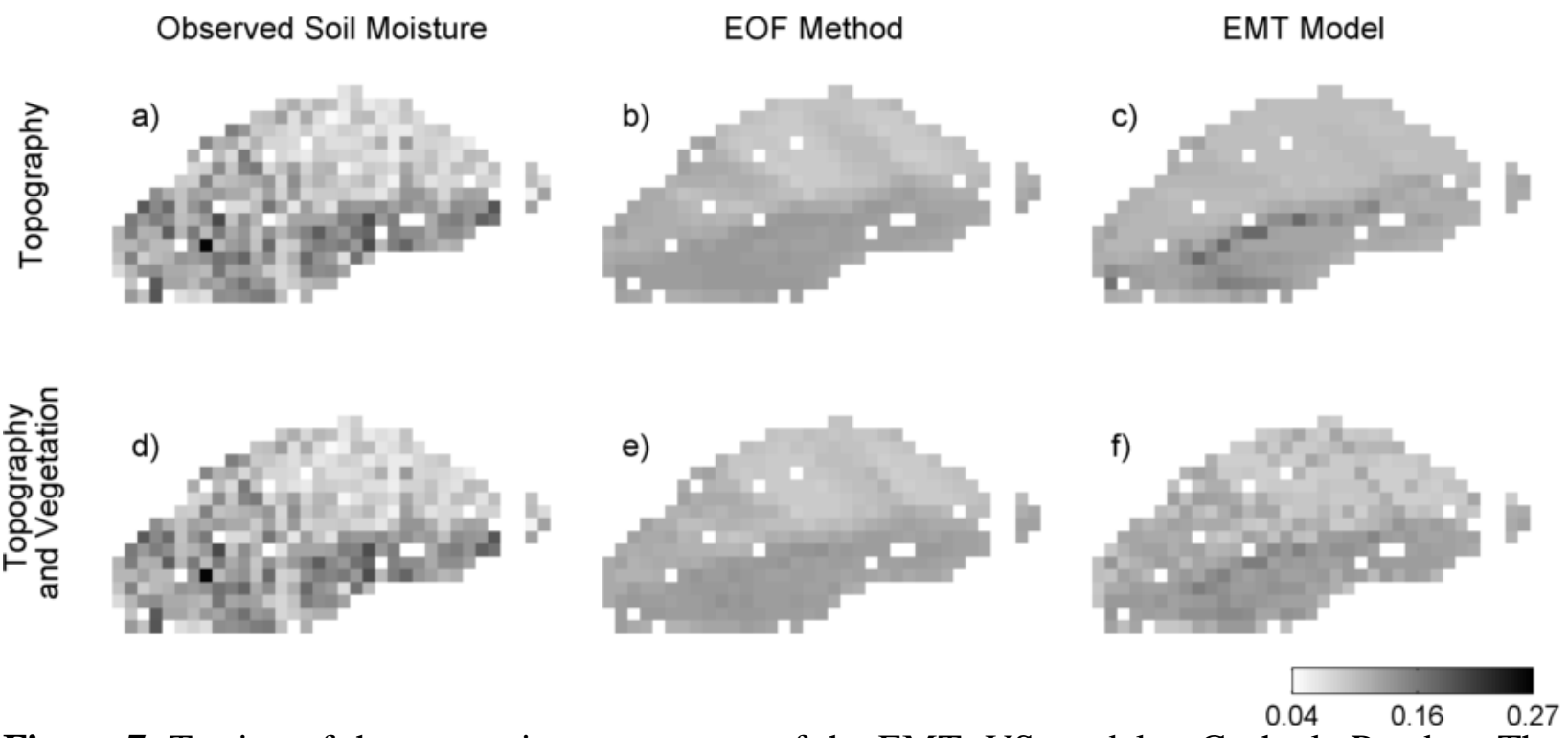

Figure 7. Testing of the vegetation component of the EMT+VS model at Cache la Poudre. The first column shows the soil moisture pattern that is observed at Cache la Poudre on June 12, 2008 with intermediate conditions, the second column shows the soil moisture patterns that are downscaled by the EOF method, and the third column shows the soil moisture patterns that are downscaled by the (c) EMT and (f) EMT+VS models. In the top row, only fine-scale topographic information is used. In the bottom row, both fine-scale topographic and vegetation information are used. All patterns are on a $15 \mathrm{~m}$ grid. 


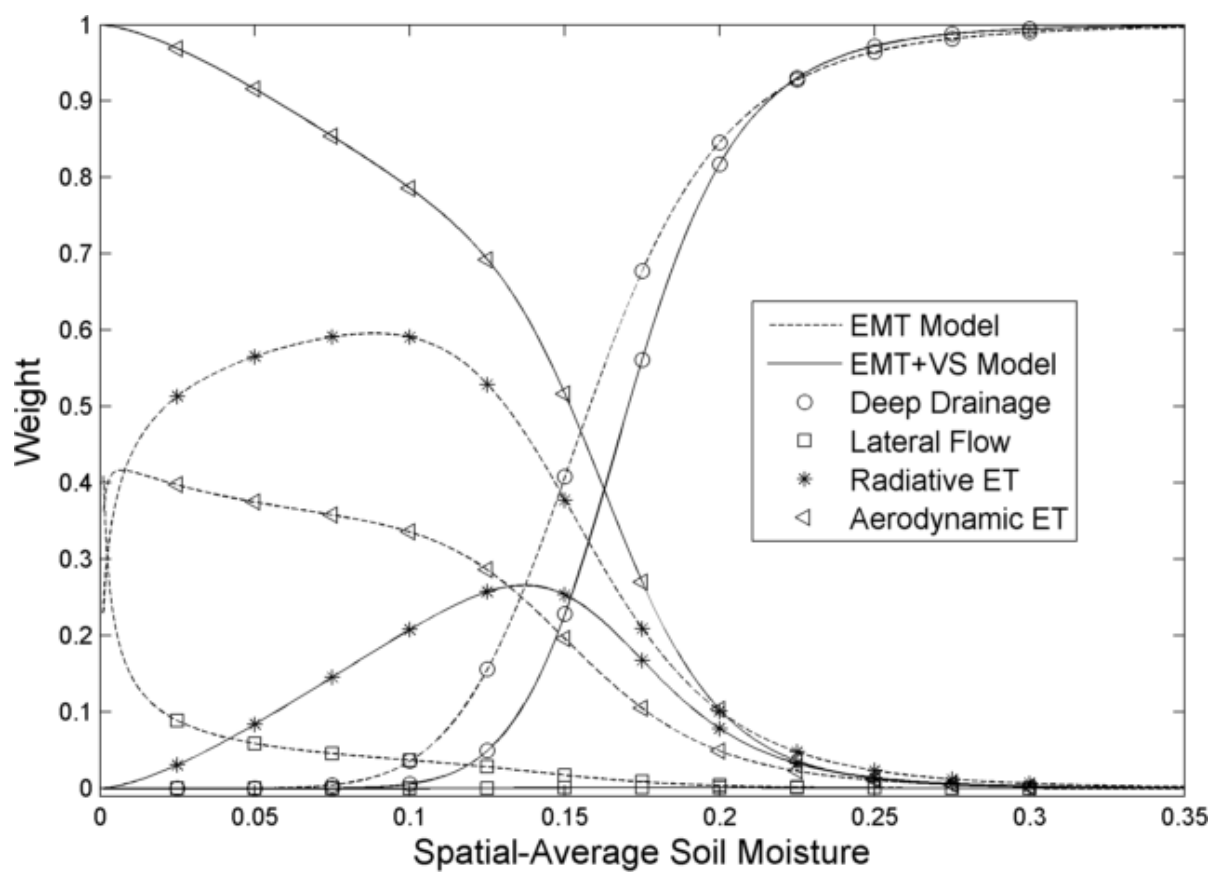

Figure 8. Calibrated weights for the Cache la Poudre catchment as a function of spatial-average soil moisture with dashed lines representing the EMT model and solid lines representing the EMT+VS model. The x-axis is positioned slightly below zero to better show weights that are zero. 


\section{EMT Model}

a) LFI

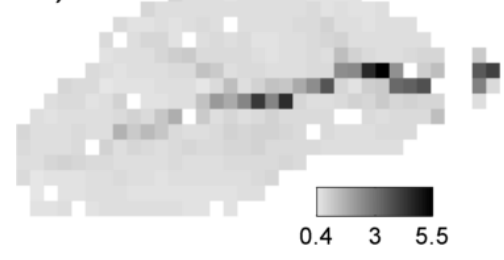

b) ETI

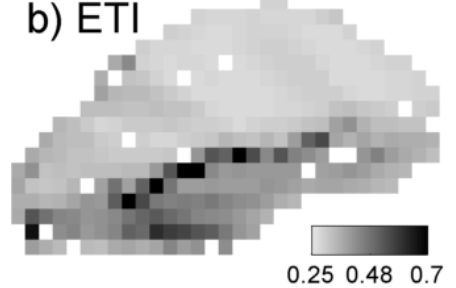

\section{EMT+VS Model}

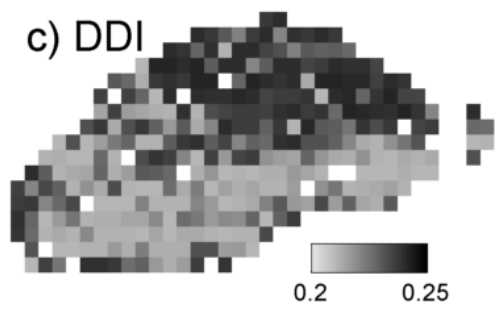

d) LFI

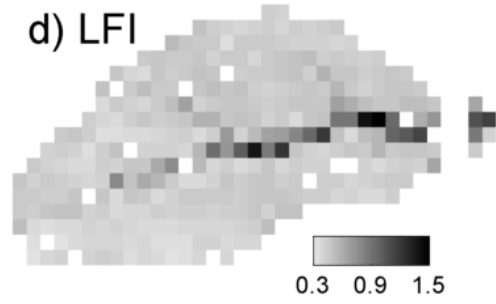

e) REI
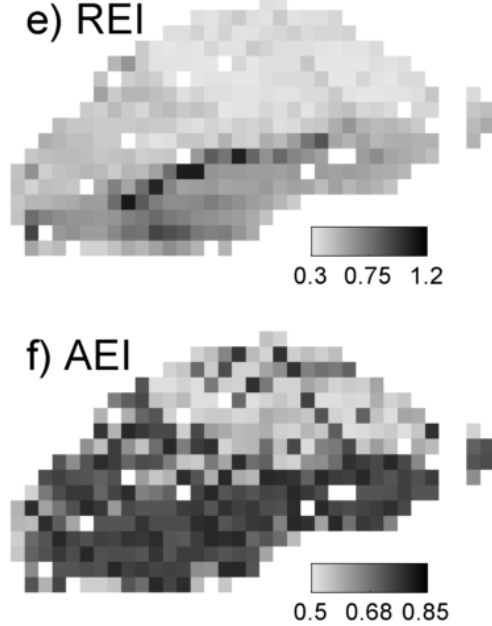

Figure 9. Comparison of indices of EMT model and EMT+VS model. The first column shows the calibrated patterns of variation that are used to downscale soil moisture in the EMT model, and the second column shows the calibrated patterns of variation that are used in the EMT+VS model. Deep drainage and aerodynamic ET produce spatially constant soil moisture in the EMT model, so only two patterns are used. The index related to radiative ET in the EMT model is termed ETI while it is termed REI in the EMT+VS model. All patterns are on a $15 \mathrm{~m}$ grid. 
Observed Soil Moisture
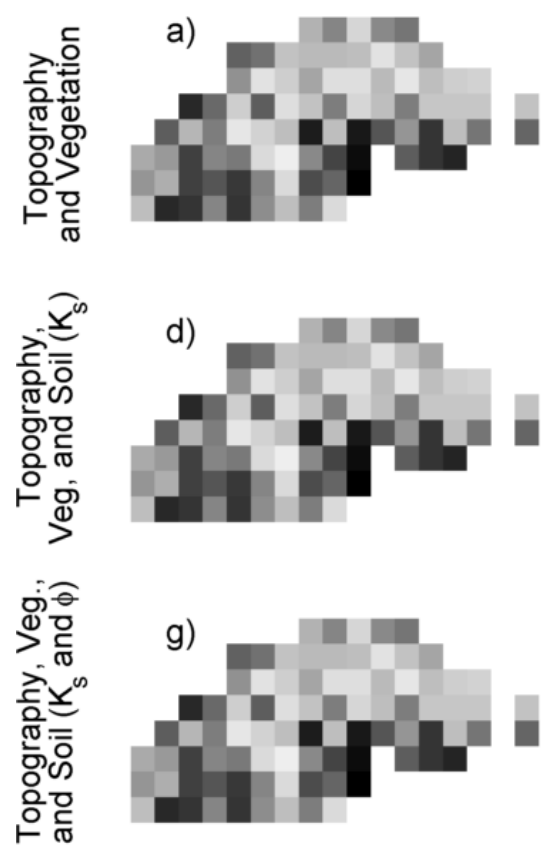

EOF Method
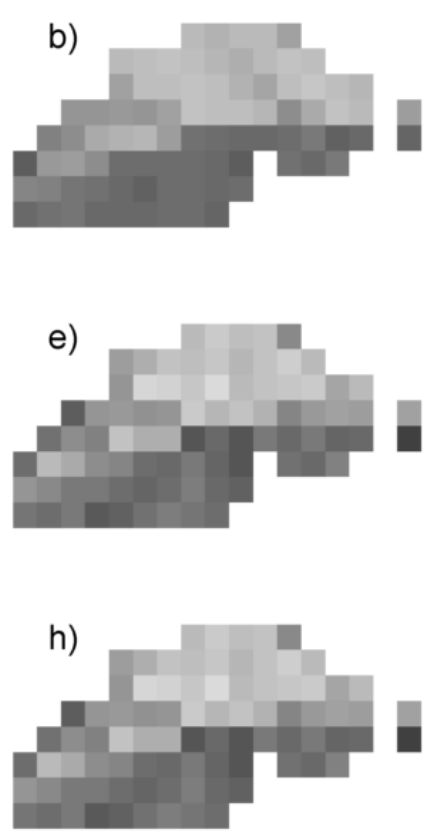

EMT+VS Model
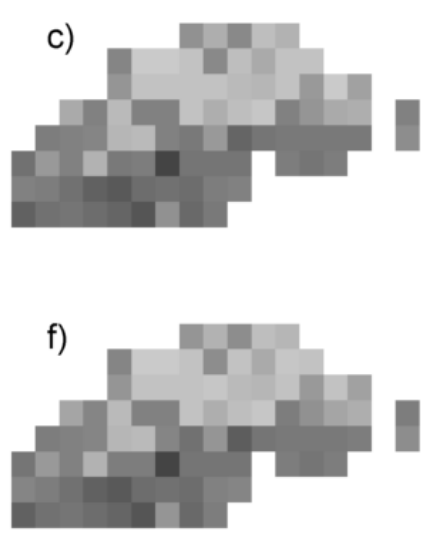

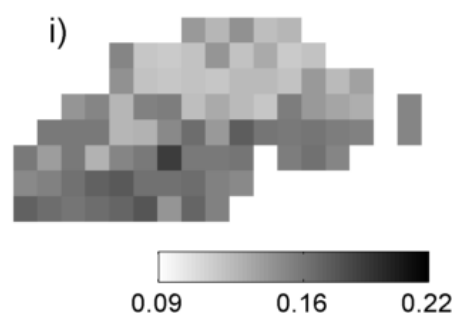

Figure 10. Testing of the vegetation and soil components of the EMT+VS model at Cache la Poudre. The first column shows the soil moisture pattern that is observed at Cache la Poudre on June 9, 2008 with wet conditions, the second column shows the soil moisture patterns that are downscaled by the EOF method, and the third column shows the soil moisture patterns that are downscaled by the EMT+VS model. In the top row, fine-scale topographic and vegetation information are used. In the middle row, fine-scale topographic, vegetation, and soil $\left(K_{s, v}\right)$ information are used. In the bottom row, fine-scale topographic, vegetation, and soil ( $K_{s, v}$ and $\phi$ ) information are used. All patterns are on a $30 \mathrm{~m}$ grid. 

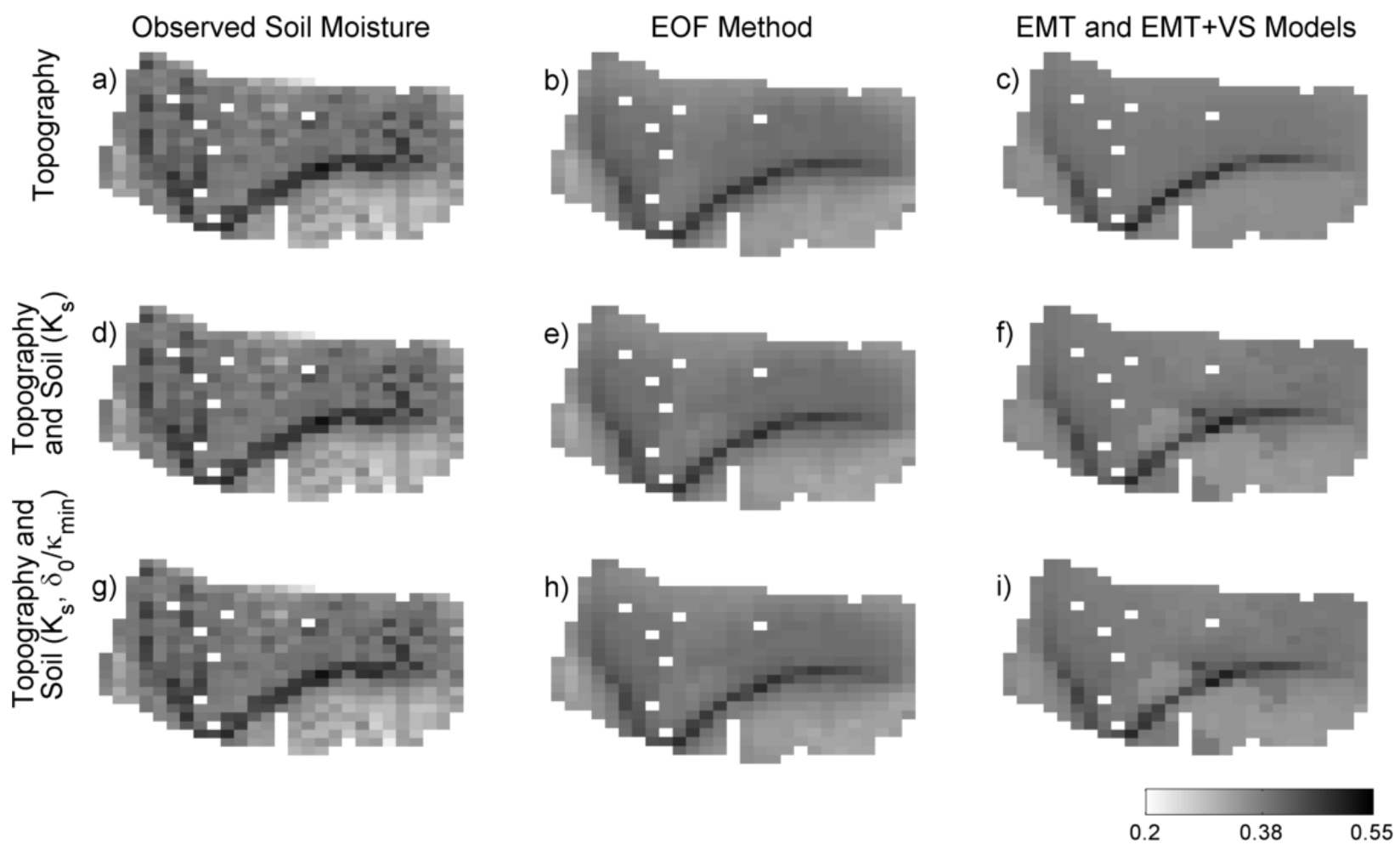

Figure 11. Testing of the soil components of the EMT+VS model at Tarrawarra. The first column shows the soil moisture pattern that is observed at Tarrawarra on September 27, 1995 with intermediate conditions, the second column shows the soil moisture patterns that are downscaled by the EOF method, and the third column shows the soil moisture patterns that are downscaled by the EMT and EMT+VS models. In the top row, fine-scale topographic information is used. In the middle row, fine-scale topographic and soil $\left(K_{s, v}\right)$ information are used. In the bottom row, fine-scale topographic and soil $\left(K_{s, v}\right.$ and $\left.\delta_{0} / \kappa_{\text {min }}\right)$ information are used. All patterns are on a 10 by $20 \mathrm{~m}$ grid. 

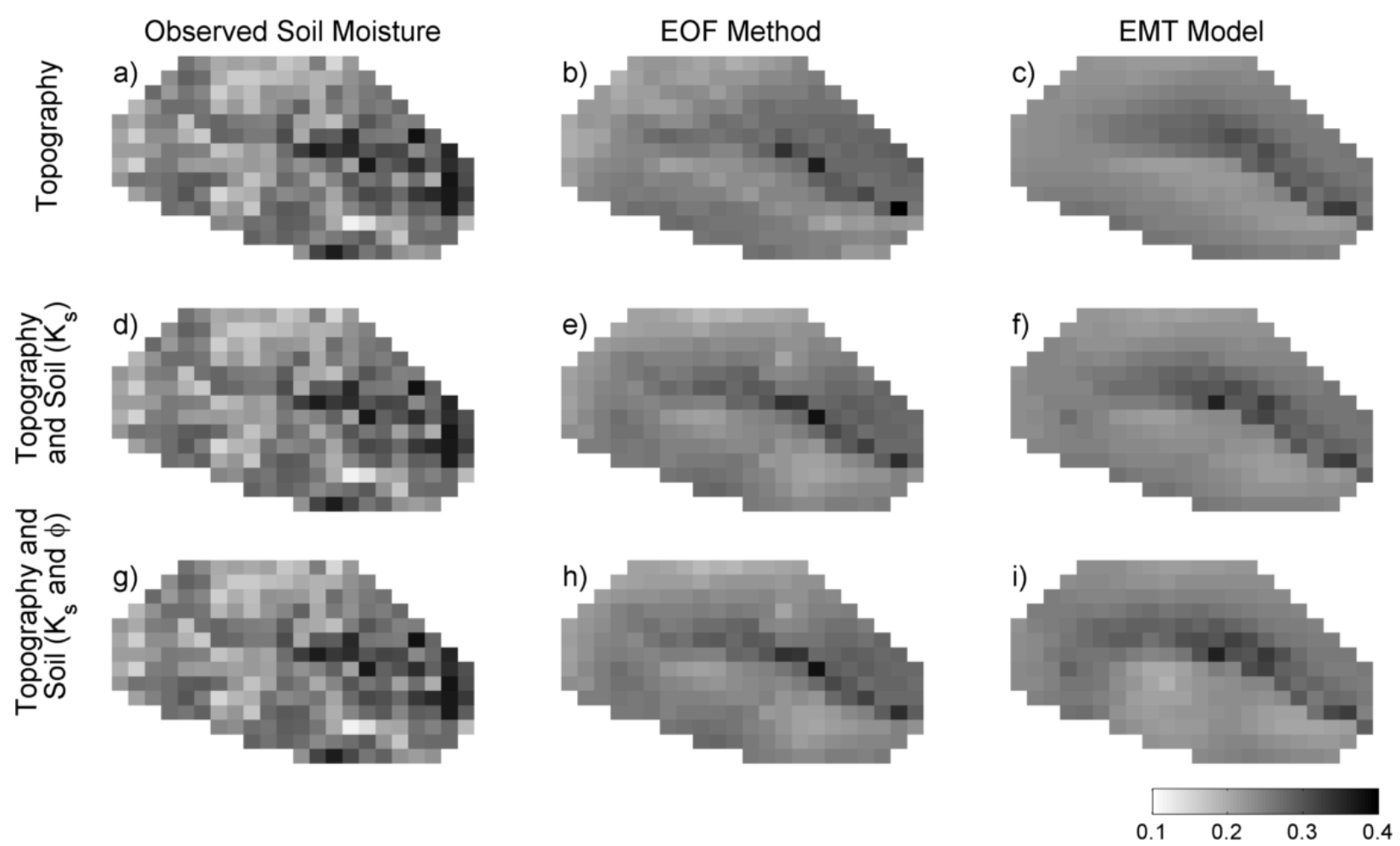

Figure 12. Testing of the soil components of the EMT+VS model at Nerrigundah. The first column shows the soil moisture pattern that is observed at Nerrigundah on September 12, 1997 with intermediate conditions, the second column shows the soil moisture patterns that are downscaled by the EOF method, and the third column shows the soil moisture patterns that are downscaled by the EMT and EMT+VS models. In the top row, fine-scale topographic information is used. In the middle row, fine-scale topographic and soil $\left(K_{s, v}\right)$ information are used. In the bottom row, fine-scale topographic and soil ( $K_{s, v}$ and $\left.\phi\right)$ information are used. All patterns are on a $20 \mathrm{~m}$ grid. 


\section{REFERENCES}

Asner GP, Scurlock JMO, A. Hicke J. 2003. Global synthesis of leaf area index observations: implications for ecological and remote sensing studies. Global Ecology and Biogeography, 12: 191-205. DOI: 10.1046/j.1466-822X.2003.00026.x.

Baroni G, Ortuani B, Facchi A, Gandolfi C. 2013. The role of vegetation and soil properties on the spatio-temporal variability of the surface soil moisture in a maize-cropped field. Journal of Hydrology, 489: 148-159. DOI: 10.1016/j.jhydrol.2013.03.007.

Bastiaanssen W, Pelgrum H, Wang J, Ma Y, Moreno J, Roerink G, Van der Wal T. 1998. A remote sensing surface energy balance algorithm for land (SEBAL).: Part 2: Validation. Journal of Hydrology, 212: 213-229.

Brocca L, Morbidelli R, Melone F, Moramarco T. 2007. Soil moisture spatial variability in experimental areas of central Italy. Journal of Hydrology, 333: 356-373. DOI: 10.1016/j.jhydrol.2006.09.004.

Burt TP, Butcher DP. 1985. Topographic controls of soil moisture distributions. Journal of Soil Science, 36: 469-486. DOI: 10.1111/j.1365-2389.1985.tb00351.x.

Busch FA, Niemann JD, Coleman M. 2012. Evaluation of an empirical orthogonal functionbased method to downscale soil moisture patterns based on topographical attributes. Hydrological Processes, 26: 2696-2709. DOI: 10.1002/hyp.8363.

Campbell GS. 1974. A simple method for determining unsaturated conductivity from moisture retention data. Soil science, 117: 311-314. 
Carlson TN, Ripley DA. 1997. On the relation between NDVI, fractional vegetation cover, and leaf area index. Remote Sensing of Environment, 62: 241-252. DOI: 10.1016/S00344257(97)00104-1.

Chen TF, Wang XS. 2012. A correlation model on plant water consumption and vegetation index in Mu Us Desert, in China. Procedia Environmental Sciences, 13: 1517-1526. DOI: 10.1016/j.proenv.2012.01.144.

Coleman ML, Niemann JD. 2012. An evaluation of nonlinear methods for estimating catchmentscale soil moisture patterns based on topographic attributes. Journal of Hydroinformatics, 14.

Coleman ML, Niemann JD. 2013. Controls on topographic dependence and temporal instability in catchment-scale soil moisture patterns. Water Resources Research, 49: 1625-1642. DOI: $10.1002 /$ wrcr.20159.

Cosby BJ, Hornberger GM, Clapp RB, Ginn TR. 1984. A Statistical Exploration of the Relationships of Soil-Moisture Characteristics to the Physical-Properties of Soils. Water Resources Research, 20: 682-690. DOI: Doi 10.1029/Wr020i006p00682.

Cristea NC, Kampf SK, Burges SJ. 2012. Revised coefficients for Priestley-Taylor and MakkinkHansen equations for estimating daily reference evapotranspiration. Journal of Hydrologic Engineering, 18: 1289-1300.

Downer C, Ogden F. 2004. GSSHA: Model To Simulate Diverse Stream Flow Producing Processes. Journal of Hydrologic Engineering, 9: 161-174. DOI:

doi:10.1061/(ASCE)1084-0699(2004)9:3(161). 
Downer, C. W., Ogden, F. L., and Byrd, A.R. 2008, GSSHAWIKI User's Manual, Gridded Surface Subsurface Hydrologic Analysis Version 4.0 for WMS 8.1, ERDC Technical Report, Engineer Research and Development Center, Vicksburg, Mississippi.

Dunkerley D. 2000. Hydrologic effects of dryland shrubs: defining the spatial extent of modified soil water uptake rates at an Australian desert site. Journal of Arid Environments, 45: $159-172$.

Eichinger WE, Parlange MB, Stricker H. 1996. On the Concept of Equilibrium Evaporation and the Value of the Priestley-Taylor Coefficient. Water Resources Research, 32: 161-164. DOI: $10.1029 / 95 w r 02920$.

Entekhabi D, Njoku EG, O'Neill PE, Kellogg KH, Crow WT, Edelstein WN, Entin JK, Goodman SD, Jackson TJ, Johnson J, Kimball J, Piepmeier JR, Koster RD, Martin N, McDonald KC, Moghaddam M, Moran S, Reichle R, Shi JC, Spencer MW, Thurman SW, Leung T, Van Zyl J. 2010. The Soil Moisture Active Passive (SMAP) Mission. Proceedings of the IEEE, 98: 704-716. DOI: 10.1109/jproc.2010.2043918.

Famiglietti JS, Rudnicki JW, Rodell M. 1998. Variability in surface moisture content along a hillslope transect: Rattlesnake Hill, Texas. Journal of Hydrology, 210: 259-281. DOI: 10.1016/S0022-1694(98)00187-5.

Fitts, C.R., 2002. Groundwater Science. Academic Press, London, UK and San Diego, CA, 450 pp.

Gerrits AMJ, Savenije HHG. 2011. Forest Floor Interception. In: Forest Hydrology and Biogeochemistry, Levia DF, Carlyle-Moses D, Tanaka T (eds.) Springer Netherlands, pp: 445-454.

Gómez-Plaza A, Alvarez-Rogel J, Albaladejo J, Castillo VM. 2000. Spatial patterns and temporal stability of soil moisture across a range of scales in a semi-arid environment. 
Hydrological Processes, 14: 1261-1277. DOI: 10.1002/(sici)1099-

1085(200005)14:7<1261::aid-hyp40>3.0.co;2-d.

Gómez-Plaza A, Martínez-Mena M, Albaladejo J, Castillo VM. 2001. Factors regulating spatial distribution of soil water content in small semiarid catchments. Journal of Hydrology, 253: 211-226. DOI: 10.1016/S0022-1694(01)00483-8.

Grayson RB, Western AW, Chiew FHS, Blöschl G. 1997. Preferred states in spatial soil moisture patterns: Local and nonlocal controls. Water Resources Research, 33: 2897-2908. DOI: 10.1029/97wr02174.

Guswa AJ. 2012. Canopy vs. Roots: Production and Destruction of Variability in Soil Moisture and Hydrologic Fluxes. gsvadzone, 11: -. DOI: 10.2136/vzj2011.0159.

He L, Ivanov VY, Bohrer G, Maurer KD, Vogel CS, Moghaddam M. 2014. Effects of fine-scale soil moisture and canopy heterogeneity on energy and water fluxes in a northern temperate mixed forest. Agricultural and Forest Meteorology, 184: 243-256. DOI: 10.1016/j.agrformet.2013.10.006.

Heimsath AM, E. Dietrich W, Nishiizumi K, Finkel RC. 1999. Cosmogenic nuclides, topography, and the spatial variation of soil depth. Geomorphology, 27: 151-172. DOI: 10.1016/S0169-555X(98)00095-6.

Hignett CS, Evett S. 2008. Field Estimation of Soil Water Content: A Practical Guide to Methods, Instrumentation and Sensor Technology. Training Course Series, 30. International Atomic Energy Agency, Vienna, Austria.

Hupet F, Vanclooster M. 2002. Intraseasonal dynamics of soil moisture variability within a small agricultural maize cropped field. Journal of Hydrology, 261: 86-101. DOI: 10.1016/S0022-1694(02)00016-1. 
Kerr YH, Waldteufel P, Wigneron JP, Martinuzzi J, Font J, Berger M. 2001. Soil moisture retrieval from space: the Soil Moisture and Ocean Salinity (SMOS) mission. Geoscience and Remote Sensing, IEEE Transactions on, 39: 1729-1735. DOI: 10.1109/36.942551.

Kidron GJ, Gutschick VP. 2013. Soil moisture correlates with shrub-grass association in the Chihuahuan Desert. CATENA, 107: 71-79. DOI: 10.1016/j.catena.2013.02.001.

Kozak JA, Ahuja LR, Green TR, Ma L. 2007. Modelling crop canopy and residue rainfall interception effects on soil hydrological components for semi-arid agriculture. Hydrological Processes, 21: 229-241. DOI: 10.1002/hyp.6235.

Kurc SA, Small EE. 2004. Dynamics of evapotranspiration in semiarid grassland and shrubland ecosystems during the summer monsoon season, central New Mexico. Water Resources Research, 40.

Lehman B, Niemann J. 2008. Spatial Patterns of in a Semi-Arid Montane Catchment with Aspect-Dependent Vegetation. In: First International Conference on Hydropedology, State College, Pennsylvania.

Li L, Gaiser PW, Gao B-C, Bevilacqua RM, Jackson TJ, Njoku EG, Rudiger C, Calvet J-C, Bindlish R. 2010. WindSat global soil moisture retrieval and validation. Geoscience and Remote Sensing, IEEE Transactions on, 48: 2224-2241.

Liang X, Lettenmaier DP, Wood EF, Burges SJ. 1994. A simple hydrologically based model of land surface water and energy fluxes for general circulation models. Journal of Geophysical Research: Atmospheres, 99: 14415-14428. DOI: 10.1029/94jd00483.

Lin BB. 2010. The role of agroforestry in reducing water loss through soil evaporation and crop transpiration in coffee agroecosystems. Agricultural and Forest Meteorology, 150: 510518. DOI: 10.1016/j.agrformet.2009.11.010. 
Martínez García G, Pachepsky YA, Vereecken H. 2014. Effect of soil hydraulic properties on the relationship between the spatial mean and variability of soil moisture. Journal of Hydrology. DOI: 10.1016/j.jhydrol.2014.01.069.

Mascaro G, Vivoni ER, Deidda R. 2010. Downscaling soil moisture in the southern Great Plains through a calibrated multifractal model for land surface modeling applications. Water Resources Research, $\mathbf{4 6 .}$

Merlin O, Escorihuela MJ, Mayoral MA, Hagolle O, Al Bitar A, Kerr Y. 2013. Self-calibrated evaporation-based disaggregation of SMOS soil moisture: An evaluation study at $3 \mathrm{~km}$ and 100m resolution in Catalunya, Spain. Remote Sensing of Environment, 130: 25-38. DOI: $10.1016 /$ j.rse.2012.11.008.

Naithani KJ, Baldwin DC, Gaines KP, Lin H, Eissenstat DM. 2013. Spatial Distribution of Tree Species Governs the Spatio-Temporal Interaction of Leaf Area Index and Soil Moisture across a Forested Landscape. PloS one, 8: e58704.

Nash J, Sutcliffe J. 1970. River flow forecasting through conceptual models part I—A discussion of principles. Journal of Hydrology, 10: 282-290.

Njoku EG, Jackson TJ, Lakshmi V, Chan TK, Nghiem SV. 2003. Soil moisture retrieval from AMSR-E. Geoscience and Remote Sensing, IEEE Transactions on, 41: 215-229. DOI: 10.1109/tgrs.2002.808243.

Omernik JM. 1987. Ecoregions of the conterminous United States. Annals of the Association of American geographers, 77: 118-125.

Pariente S. 2002. Spatial Patterns of Soil Moisture as Affected by Shrubs, in Different Climatic Conditions. Environ Monit Assess, 73: 237-251. DOI: 10.1023/a:1013119405441. 
Penman HL. 1948. Natural evaporation from open water, bare soil and grass. Proceedings of the Royal Society of London. Series A. Mathematical and Physical Sciences, 193: 120-145.

Peters-Lidard C, Zion M, Wood E. 1997. A soil-vegetation-atmosphere transfer scheme for modeling spatially variable water and energy balance processes. Journal of Geophysical Research: Atmospheres (1984-2012), 102: 4303-4324.

Priestley C, Taylor R. 1972. On the assessment of surface heat flux and evaporation using largescale parameters. Monthly weather review, 100: 81-92.

Ritchie JT. 1972. Model for predicting evaporation from a row crop with incomplete cover. Water Resources Research, 8: 1204-1213. DOI: 10.1029/WR008i005p01204.

Scott C, Bastiaanssen W, Ahmad M. 2003. Mapping Root Zone Soil Moisture Using Remotely Sensed Optical Imagery. Journal of Irrigation and Drainage Engineering, 129: 326-335. DOI: doi:10.1061/(ASCE)0733-9437(2003)129:5(326).

Takagi K, Lin HS. 2011. Temporal Dynamics of Soil Moisture Spatial Variability in the Shale Hills Critical Zone Observatory. Vadose Zone Journal, 10: 832-842. DOI: 10.2136/vzj2010.0134.

Traff D. 2013. Effects of woody vegetation on shallow soil moisture at a semiarid montane catchment. Thesis. Colorado State University.

Tromp-van Meerveld HJ, McDonnell JJ. 2006. On the interrelations between topography, soil depth, soil moisture, transpiration rates and species distribution at the hillslope scale. Advances in Water Resources, 29: 293-310. DOI: 10.1016/j.advwatres.2005.02.016. Walker JP. 1999. Estimating soil moisture profile dynamics from near-surface soil moisture measurements and standard meteorological data. Diss. University of Newcastle. 
Walker JP, Willgoose GR, Kalma JD. 2001. The Nerrigundah data set: Soil moisture patterns, soil characteristics, and hydrological flux measurements. Water Resources Research, 37: 2653-2658.

Wallace JS, Jackson NA, Ong CK. 1999. Modelling soil evaporation in an agroforestry system in Kenya. Agricultural and Forest Meteorology, 94: 189-202. DOI: 10.1016/S01681923(99)00009-X.

Werbylo KL, Niemann JD. 2014. Evaluation of sampling techniques to characterize topographically-dependent variability for soil moisture downscaling. Journal of Hydrology. DOI: 10.1016/j.jhydrol.2014.01.030.

Western AW, Grayson RB. 1998. The Tarrawarra Data Set: Soil moisture patterns, soil characteristics, and hydrological flux measurements. Water Resources Research, 34: 2765-2768. DOI: 10.1029/98wr01833.

Western AW, Grayson RB, Blöschl G, Willgoose GR, McMahon TA. 1999. Observed spatial organization of soil moisture and its relation to terrain indices. Water Resources Research, 35: 797-810. DOI: 10.1029/1998wr900065.

Wigmosta MS, Vail LW, Lettenmaier DP. 1994. A distributed hydrology-vegetation model for complex terrain. Water Resources Research, 30: 1665-1679. DOI: 10.1029/94wr00436.

Wilson DJ, Western AW, Grayson RB. 2005. A terrain and data-based method for generating the spatial distribution of soil moisture. Advances in Water Resources, 28: 43-54. DOI: 10.1016/j.advwatres.2004.09.007.

Xu X-L, Ma K-M, Fu B-J, Song C-J, Liu W. 2008. Relationships between vegetation and soil and topography in a dry warm river valley, SW China. CATENA, 75: 138-145. DOI: 10.1016/j.catena.2008.04.016. 
Zhu Q, Lin H. 2011. Influences of soil, terrain, and crop growth on soil moisture variation from transect to farm scales. Geoderma, 163: 45-54. DOI: 10.1016/j.geoderma.2011.03.015.

Zreda M, Desilets D, Ferré TPA, Scott RL. 2008. Measuring soil moisture content non invasively at intermediate spatial scale using cosmic-ray neutrons. Geophysical Research Letters, 35: L21402. DOI: 10.1029/2008g1035655. 